
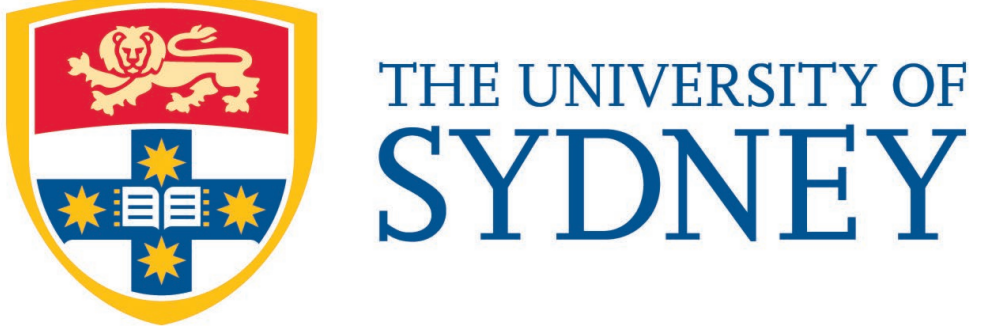

Economics Working Paper Series

2019 - 13

Collusion, price dispersion, and fringe competition

Nicolas de Roos and Vladimir Smirnov

September 2019 


\title{
Collusion, price dispersion, and fringe competition*
}

\author{
Nicolas de Roos ${ }^{\dagger}$ \\ Vladimir Smirnov ${ }^{\ddagger}$ \\ Sydney University \\ Sydney University
}

September 16, 2019

\begin{abstract}
We study the optimal behaviour of a cartel faced with fringe competition and imperfectly attentive consumers. Intertemporal price dispersion obfuscates consumer price comparison which aids the cartel through two channels: it reduces the effectiveness of free riding by the fringe; and it relaxes the cartel's internal incentive constraints. Our theory explains the survival of a price-setting cartel in a homogeneous product market, provides a collusive rationale for sales and Edgeworth cycles, and characterises the cartel's manipulation of its fringe rival through a double cut-off rule.
\end{abstract}

JEL Classification: L13, D83

Keywords: Collusion, fringe competition, obfuscation, price dispersion.

${ }^{*}$ We are grateful to Murali Agastya, Simon Grant, Abhijit Sengupta, Kunal Sengupta and Andrew Wait; seminar participants at the University of Queensland and the University of Wellington; and conference participants at the Australasian Economic Theory workshop for useful comments, suggestions and encouragement.

${ }^{\dagger}$ School of Economics, Social Sciences Building A02, University of Sydney, NSW 2006, Australia, e-mail: nicolas.deroos@sydney.edu.au.

${ }^{\ddagger}$ School of Economics, Social Sciences Building A02, University of Sydney, NSW 2006, Australia, e-mail: vladimir.smirnov@sydney.edu.au. 


\section{Introduction}

Repeated interaction between firms is ubiquitous, and industries are often concentrated. The theory of collusion therefore has broad relevance for industry interaction. Theory typically presumes full membership of a cartel. ${ }^{1}$ However, as Bos and Harrington (2010) argue, incomplete membership is probably the norm for explicit cartels. ${ }^{2}$ For example, the international Vitamin C cartel, operating from 1991 to 1995, was ultimately destroyed by the persistent price undercutting of Chinese firms operating outside the cartel (de Roos, 2001). The Vitamin B1 cartel also suffered substantial market share losses at the hands of excluded Chinese competitors (Bos and Harrington, 2010). The difficulties faced by the OPEC cartel due to incomplete membership are well known. Moving beyond explicit cartels, industries are often concentrated, but rarely completely controlled by a small number of firms. To illustrate, based on the 2007 U.S. Census, over 23 per cent of industries have an 8-firm concentration above 0.5 and a 20 -firm concentration lower than $0.9{ }^{3}$ Whether considering settings of explicit or implicit coordination, theory must therefore account for the potentially irritating presense of fringe firms who operate outside the remit of coordination.

If firms produce homogeneous products and compete in prices, an incomplete cartel poses a challenge for theory: what explains its survival? Standard arguments establish a spectrum of profitable equilibria for a patient cartel with complete membership. However, profitable equilibria are not available for an incomplete cartel. Much of the literature on incomplete cartels sidesteps this issue by considering a price-taking fringe (e.g. D'Aspremont et al. (1983); Donsimoni et al. (1986)), or a Cournot fringe (e.g. Shaffer (1995); Martin (1990)). ${ }^{4}$ Alternatively, cartel survival is possible if the fringe is restricted by capacity constraints (e.g. D’Aspremont and Gabszewicz (1985), Lambson (1994), Bos and Harrington (2010), de Roos (2001)).

In this paper, we consider a price-setting cartel operating in a homogeneous product market, impinged by a strategic fringe that is not encumbered by capacity constraints. Cartel survival is possible due to consumer inattention. In our model, a cartel engages in infinitely

\footnotetext{
${ }^{1}$ While fringe competition is often neglected, the problem of a cartel or dominant firm subject to fringe competition has a long tradition. Early examples include Markham (1951) and Arant (1956).

${ }^{2}$ Additional details can be found in the cross-cartel studies of Hay and Kelley (1974) and Griffin (1989) and the recent case evidence of Harrington (2006).

${ }^{3}$ To calculate concentrations, we use an 8-digit NAICS-based classification, omitting mining, construction, and manufacturing industries. Using the same source, over 13 per cent of industries have a 4 -firm concentration above 0.5 and a 20 -firm concentration below 0.9 .

${ }^{4}$ In finite resource extraction games between a cartel and a fringe, a price-taking or Cournot fringe is also typically assumed. See, for example Salant (1976), Benchekroun and Withagen (2012) and Benchekroun et al. (2019).
} 
repeated price competition with a statically optimising player. Consumers are imperfectly attentive in the manner of de Roos and Smirnov (forthcoming). In particular, consumer attention is triggered only by prices that are unusually low relative to recent experience. In this environment, if prices are fixed over time, price differences are easy to discern; while intertemporally dispersed price patterns are less amenable to price comparison. Exploiting this setting, the cartel strategically employs a dispersed price path to obfuscate price comparison efforts of consumers.

The combination of homogeneous products and imperfect consumer attentiveness gives rise to two contrasting temptations. With identical products, cartel members have an incentive to undercut the cartel price to obtain a discrete increase in market share. Alternatively, a cartel member who sets a higher price than her peers may still attract unwitting customers, providing an incentive to relent. Cartel policies must therefore guard against both temptations, giving rise to two distinct sets of incentive constraints. The fringe is beset by similar motives, and it is here that the cartel is able to manipulate the fringe. By crafting the path of prices, the cartel can induce the fringe to either undercut the cartel price or relent.

We provide two main contributions to the literature. First, we characterise the optimal dynamic price path of a cartel faced with both fringe competition and imperfectly attentive consumers. We show that the optimal price path involves intertemporal price dispersion. In the presence of the fringe, the profitability of a cartel employing a fixed price path is severely restricted. Without price variation, price differences are obvious to consumers and the fringe has an incentive to undercut the cartel price and capture the entire market. By introducing price variation, the cartel reduces consumer responsiveness to price differences, ensuring it prospers despite undercutting by the fringe. The optimal path is an infinitely repeated price cycle, described by a set of complementary slackness conditions. In each period of a sequence, cartel members either set the monopoly price or weakly decrease prices. Price dispersion is most efficiently achieved through sales, allowing the cartel to enjoy monopoly prices for extended periods, interrupted by temporary price reductions. The most robust structure to deter internal deviation is an Edgeworth cycle in which the cartel reduces price in each period of a sequence.

Our second, related, contribution is to provide an alternative explanation for the survival of an incomplete cartel setting prices in a homogeneous products market. With imperfect consumer attentiveness, cartel profitability is still possible despite a fringe that undercuts the cartel price. Imperfect attentiveness plays a similar role to capacity constraints in the sense that both permit residual demand for a high-priced firm. However, there are subtle differences. While capacity constraints are typically exogenously imposed in the literature on incomplete cartels, in our model the impact of consumer inattention is endogenously 
determined by the collective actions of cartel members. In particular, a dispersed price path accentuates the competition-softening role of inattention. Further, our model gives rise to a qualitative difference in the strategic interaction between the fringe and the cartel. In the presence of a capacity-constrained fringe, the cartel price acts as an umbrella, allowing the fringe to price below it and operate at capacity (Bos and Harrington, 2010). In our model, the cartel may manipulate the fringe by adjusting the level of prices in each period. High prices encourage the fringe to undercut, while low prices induce relenting. The cartel thus faces a discrete trade-off between markup and market share. We show that cartel manipulation of the fringe takes the form of a double cut-off rule. In each finite price sequence, the fringe undercuts the monopoly price observed in the first period, and the cartel decides in which period the fringe should begin and finish relenting.

Our principal insight is that obfuscation (in the form of intertemporal price dispersion) aids collusion through two mechanisms. First, it reduces the market share of a fringe choosing to undercut the cartel price, mitigating the effectiveness of free riding by the fringe. Second, it eases the cartel's internal incentive constraints by reducing the market share of a deviator contemplating undercutting the cartel price. This insight has potential implications for both tacit and explicit collusion. In the presence of explicit communication, our focus on the optimal collusive mechanism is natural. This leads to predictions about the shape of the optimal path and the nature of fringe manipulation. Without explicit communication, we expect coordination on the optimal path to be more challenging. However, our main message likely still applies. A dispersed price path reduces the incentive for major firms to rock the boat and also mitigates the disruptive influence of the fringe.

Our analysis builds on a growing literature on the role of obfuscation in oligopoly. This literature has focused mainly on non-cooperative settings. Heidhues and Kőszegi (2018) and Spiegler (2011) provide a recent survey and text treatment. Two recent papers that examine the interplay between collusion and obfuscation are most closely related to our work. Our model builds directly on the framework of de Roos and Smirnov (forthcoming) by introducing a fringe firm into the problem of a cartel facing imperfectly attentive consumers. In de Roos and Smirnov (forthcoming), consumer inattention improves the sustainability of a cartel willing to craft a dispersed price path. We reinforce this finding by introducing a second motive for price variation: price dispersion not only relaxes the cartel's internal incentive constraints, but also weakens the destructive power of the fringe. de Roos (2018) considers the problem of a cartel when faced with an alternative broad class of obfuscation mechanisms in which the comparability of rival products is endogenously determined by the collective choices of cartel members. While de Roos (2018) focuses on a complete cartel, we also expect limited comparability to be beneficial for an incomplete cartel. 
The rest of the paper is structured as follows. In Section 2, we introduce the model and describe the problem faced by the cartel and the fringe. Section 3 contains preliminary analysis and Section 4 develops our main results. We first analyse the cartel problem under the assumption that the fringe primarily engages in undercutting. We then examine the manner in which the cartel manipulates the fringe. Sections 5 and 6 contain a discussion and conclusion.

\section{The model}

The market contains $n$ firms selling an identical product over an infinite horizon. Firms in the set $\mathscr{C}=\{1, \ldots, n-1\}$ operate a price-fixing cartel, and the remaining fringe firm $n$ operates outside the cartel. In each period $t=1,2, \ldots, \infty$, each firm $j$ simultaneously chooses a price $p^{j} \in[0,1]$, leading to price vector $\mathbf{p}=\left(p^{1}, p^{2}, \ldots, p^{n}\right){ }^{5}$ Define $p_{(r)}$ as the $r^{\text {th }}$ lowest price in p. Cartel members discount the future at the common rate $\delta \in(0,1)$, while the fringe firm behaves myopically. All firms have constant marginal costs, which we normalise to zero.

A continuum of consumers of measure 1 each purchase a single unit of the good. Consumers are imperfectly attentive towards prices. They have an impression of the price distribution, but do not recall specific prices unless they are unusual or attractive. In particular, consumers observe all prices equal to or below a threshold $y$, but only recall higher prices with positive probability. If the lowest price is below the threshold, consumer attention is piqued, and all consumers buy from a firm setting the lowest price. If, instead, all prices are above the threshold, not all consumers will buy from the lowest available price. We formalise these ideas with Assumption 1. Part 3) of the assumption introduces the salience of unusually low prices.

Assumption 1 (de Roos and Smirnov (forthcoming)).

1. All firms setting the same price obtain the same market share.

2. If $p^{j}<p^{i}$, then the market share of firm $j$ is at least as great as the share of firm $i$.

3. If $p_{(1)} \leq y$, then all firms setting a price above $p_{(1)}$ obtain a market share of zero.

4. If $p_{(1)}>y_{t}$, then market shares depend only on the rank order of the price vector.

Firm $j$ receives profits

$$
\pi^{j}\left(\mathbf{p}, y_{t}\right)=p^{j} s^{j}\left(\mathbf{p}, y_{t}\right)
$$

\footnotetext{
${ }^{5}$ The upper bound of 1 on the price support could be interpreted as a choke or monopoly price.
} 
where $s^{j}\left(\mathbf{p}, y_{t}\right)$ is the market share of firm $j$, and the cut-off $y_{t}$ in period $t$ is determined by the lowest price observed in the previous $m$ periods:

$$
y_{t}=\min _{\tau \in\{t-m, \ldots, t-1\}, j} p_{\tau}^{j} .
$$

Combining Assumption 1 and equation (2), consumer attention is triggered by unusually low prices relative to recent experience.

Each firm $j$ simultaneously chooses a price $p^{j} \in A_{j}=[0,1]$, with set of pure action profiles $A=\prod_{j} A_{j}$. Let $\mathscr{H}^{t}=A^{t}$ be the set of $t$-period histories. The set of possible histories is then $\mathscr{H}=\cup_{t=0}^{\infty} \mathscr{H}^{t}$. We focus on pure symmetric strategies for all participants. ${ }^{6}$ A pure strategy for cartel member $j \in \mathscr{C}$ is a mapping from the set of all possible histories to the set of actions, $\sigma^{j}: \mathscr{H} \rightarrow A_{j}$. A strategy for fringe firm $j=n$ in period $t$ is a mapping from the current history to the set of actions, $\sigma_{t}^{n}: \mathscr{H}^{t} \rightarrow A_{n}$. Let $\sigma^{n}=\left(\sigma_{1}^{n}, \sigma_{2}^{n}, \ldots\right)$ be the sequence of strategies for the fringe. Given the strategy profile $\sigma=\left\{\sigma^{j}\right\}_{j=1}^{n}$, let $a_{t}^{j}(\sigma)$ be the period $t$ action for firm $j$ induced by $\sigma$, and let $a_{t}(\sigma)$ be the associated action profile. Payoffs for cartel members and the fringe are given, respectively, by

$$
\begin{aligned}
& v^{j}(\sigma)=\sum_{t=0}^{\infty} \delta^{t} \pi^{j}\left(a_{t}(\sigma), y_{t}(\sigma)\right), j \in \mathscr{C}, \\
& v_{t}^{j}(\sigma)=\pi^{j}\left(a_{t}(\sigma), y_{t}(\sigma)\right), j=n .
\end{aligned}
$$

In equilibrium, the optimising behaviour of consumers, cartel members, and the fringe firm must be consistent. We formalise equilibrium with Definition 1 . Throughout, we focus on strongly symmetric equilibria and, unless indicated, we consider pure strategies.

Definition 1. The collection $\left\{\sigma,\left\{y_{t}\right\}_{t=0}^{\infty}\right\}$ is a market equilibrium if:

1. for all $j \in \mathscr{C}$, all $h \in \mathscr{H}$, and all $\sigma^{\prime j}, v^{j}(\sigma \mid h) \geq v^{j}\left(\left(\sigma^{\prime j} ; \sigma^{-j}\right) \mid h\right)$;

2. for $j=n$, all $t$, all $h^{t} \in \mathscr{P}^{t}$, and all $\sigma^{\prime j}, v_{t}^{j}\left(\sigma \mid h^{t}\right) \geq v_{t}^{j}\left(\left(\sigma^{\prime j} ; \sigma^{-j}\right) \mid h^{t}\right)$; and

3. for all $t$, the cut-off price $y_{t}$ is given by (2).

\subsection{Discussion}

In this section, we discuss comparative statics with respect to consumer attentiveness, possible microfoundations of consumer behaviour, and robustness towards alternative model specifications.

\footnotetext{
${ }^{6}$ Coordinating on, verifying and enforcing asymmetric or mixed strategies presents additional challenges for cartels. In related work, de Roos and Smirnov (forthcoming) discuss the implications of more general cartel strategies.
} 
Consumer attentiveness may vary systematically across markets, depending on, for example, the frequency of purchase, importance of a product in the consumer budget, and prominence of price displays. We introduce the parameters $\alpha_{r}, r=1, \ldots, n$, to allow such variation. Let $\alpha_{r}$ be the market share of the firm setting $p_{(r)}$ in the event that all prices are distinct and above the threshold $y$. For instance, we may expect the market share of the lowest priced firm, $\alpha_{1}$, to depend positively on consumer attentiveness, while there is a negative relationship between attentiveness and the share of the highest priced firm, $\alpha_{n}$. For convenience, we also introduce the parameter $\beta \in[0,1]$ as an index of attentiveness. With a higher $\beta$, prices are more likely to be salient and the firm with the lowest (highest) price attracts a greater (lower) market share. We associate $\beta=1$ with perfect information, and we assign $\alpha_{1}=1$ and $\alpha_{r}=0$ for $r>1$ to this case. When $\beta=0$, consumers are minimally attentive, and we let $\alpha_{r}=1 / n$ for all $r$.

Example 1 (de Roos and Smirnov (forthcoming)). With independent probability $\beta$, consumers observe and recall each price. Each consumer purchases from the lowest-priced store that she recalls. In the event that she recalls no prices, she randomises uniformly across the $n$ stores. This results in the market shares

$$
\alpha_{r}=(1-\beta)^{r-1} \beta+(1-\beta)^{n} / n, \quad r=1, \ldots, n .
$$

In markets with more attentive consumers, the probability of observing each price, $\beta$, is higher. The market share of the lowest (highest) priced firm is monotonically increasing (decreasing) in $\beta$.

We could interpret Assumption 1 as a minor adjustment to the Bertrand rationing rule in which the lowest-price firm does not capture the entire market. Alternatively, de Roos and Smirnov (2019) provide a detailed microfoundation based on search. Before a purchase need arises, consumers are exposed to prices, but, due to bounded recall and finite memory, recall only a subset of the price vector. With this incomplete price vector as a base, consumers then engage in costly sequential search. de Roos and Smirnov (2019) show that these foundations lead to Assumption 1 with the market share parameters in (5). In addition, equilibrium predictions are robust to adjustments in the consumer memory and recall processes, and the existence of forward looking consumers.

\section{Preliminary analysis}

In this section, we describe the behaviour of the fringe firm and discuss the viability of a fixed-price cartel as a benchmark for comparison. For the remainder of the paper, we will 
identify cartel strategies consistent with market equilibrium, taking the strategy of the fringe to be well specified.

\subsection{Fringe behaviour}

We consider strongly symmetric equilibria below, so it is sufficient for us to examine fringe reactions as a function of a common cartel price. In period $t$, the fringe firm reaction function depends on the cartel price, $p_{t}$, and the cut-off price, $y_{t}$.

If $p_{t} \leq y_{t}$, then it is not possible for the fringe firm to earn positive profits by pricing above the cartel. In the special case that $p_{t}=0$, positive profits are impossible for the fringe, and any non-negative price is a best response. In the reaction function below, we assign a fringe price of zero to this case, with no implications for our results. If $0<p_{t} \leq y_{t}$, it is optimal for the fringe to marginally undercut the cartel price by setting the price $\dot{p}_{t} \equiv \max _{p} p<p_{t}{ }^{7}$

If instead $p_{t}>y_{t}$, there are three possible best responses for the fringe. Because some consumers are inattentive towards prices, the fringe can attract a positive market share by relenting to the maximum price of 1, earning profits of $\alpha_{n}$. Alternatively, by marginally undercutting the cartel price, the fringe obtains a boost in market share from attentive consumers and receives profits of approximately $\alpha_{1} p_{t}$. Finally, if the fringe undercuts the cartel all the way to the cut-off price $y_{t}$, they can capture the entire market and earn profits of $y_{t}$.

We summarise this discussion with the fringe reaction function $b$ in (6) below.

$$
b\left(p_{t}, y_{t}\right)= \begin{cases}1 & \text { if } y_{t} \leq \alpha_{n} \text { and } y_{t}<p_{t} \leq \alpha_{n} / \alpha_{1} \\ \dot{p}_{t} & \text { if } 0<p_{t} \leq y_{t} \text { or } p_{t}>\max \left\{y_{t} / \alpha_{1}, \alpha_{n} / \alpha_{1}\right\} \\ y_{t} & \text { if } \alpha_{n}<y_{t}<p_{t} \leq y_{t} / \alpha_{1} \\ 0 & \text { if } p_{t}=0 .\end{cases}
$$

For future reference, if $p_{t}>0$ and $y_{t} \leq \alpha_{n}$, then the fringe reaction function reduces to

$$
b\left(p_{t}, y_{t}\right)= \begin{cases}1 & \text { if } y_{t}<p_{t} \leq \alpha_{n} / \alpha_{1} \\ \dot{p}_{t} & \text { otherwise. }\end{cases}
$$

\subsection{A fixed-price cartel}

In a repeated game exhibiting no cost or demand variation, a cartel with a fixed price path provides a natural benchmark. Lemma 1 examines this case. To set up the lemma, define

\footnotetext{
${ }^{7}$ Here, we run into the "open-set" problem: $\dot{p}_{t}$ does not exist. As in Tirole (1988), consider the limiting case in which the fringe sets $p_{t}$, but obtains a higher market share than cartel members, consistent with a lower price.
} 
implicitly the critical discount factor $\delta_{0}$ as follows:

$$
\delta_{0}=\max \left\{\frac{n-1}{n-1+\left(1-\alpha_{n}\right) D}, 1-\frac{p\left(1-\alpha_{n}\right) D}{\alpha_{n-1}(n-1)}\right\}, \quad D=\frac{1-\delta_{0}^{m}}{1-\delta_{0}^{m+1}} .
$$

Lemma 1. Suppose consumers have no prior pricing information, $y_{1}=1$. Then,

1. there exists no market equilibrium in which $a_{t}^{j}(\sigma)=p \in\left(\alpha_{n}, 1\right]$ for all t and $j \in \mathscr{C}$; and

2. there exists a market equilibrium in which $a_{t}^{j}(\sigma)=p \leq \alpha_{n}$ for all t and $j \in \mathscr{C}$ iff $\delta \geq \delta_{0}$.

Recall from (6) that the fringe will either undercut the cartel price or relent to the maximum price. If the cartel price is fixed above the level $\alpha_{n}$, then the fringe firm prefers to undercut and capture the whole market, leaving the cartel with no profits. It is only if the cartel fixes the price at a sufficiently low level that collusion is possible, provided cartel members are patient.

Lemma 1 provides a contrast to the standard Bertrand environment. It is possible for a cartel to survive the existence of a fringe competitor in the presence of imperfectly attentive consumers. However, a fixed-price cartel suffers two limitations. First, in markets in which consumers are relatively attentive, $\alpha_{n}$ approaches zero, and the fixed price cartel is not profitable. Second, the critical discount factor $\delta_{0}$ is bounded below by $(n-1) / n$, making the cartel difficult to sustain. In the next section, we establish that intertemporal price variation raises both the profitability and sustainability of the cartel.

\section{Cyclical strategies}

We begin by considering infinitely repeated cycles of finite length. In Section 4.4, we argue that cyclical strategies are optimal in the presence of finite memory. Definition 2 specifies a grim-trigger strategy in which each cartel member repeats the $k$-period sequence $\left\{p_{1}, p_{2}, \ldots, p_{k}\right\}$ on the equilibrium path, and punishment is an optimal penal code with value 0 . For convenience, we consider cycles of length $k \leq m$. With $k \leq m$, by (2), the lowest price in the sequence is always retained in memory, and therefore the cut-off value $y$ is constant. We summarise the parameter vector with $\theta=(\beta, n, \delta, k) .^{8}$

Definition 2. In a $k$-period cycle $\sigma^{(k)}$, in period $t$ firm $j \in \mathscr{C}$ sets price

$$
p_{t}^{j}= \begin{cases}p(t) & \text { if } t=0 \text { or } p_{\tau}^{i}=p(\tau) \forall \tau<t, \forall i \\ 0 & \text { otherwise }\end{cases}
$$

\footnotetext{
${ }^{8}$ In de Roos and Smirnov (forthcoming), we discuss generalisations that carry over to the current context. In particular, we provide a formal proof of the optimality of cyclical strategies, and extend to the case $k>m$.
} 
where

$$
p(t)=p_{s} \text { if } t-s+1 \text { is divisible by } k, s=1, \ldots, k \text {, }
$$

and $p_{s} \in[0,1], s=1, \ldots, k$.

To discuss time-varying paths for $p(t)$, we introduce additional notation. Let $\pi_{s}$ and $v_{s}$ be cartel member profits and continuation values starting from period $s$ of the strategy $\sigma^{(k)}$, for $s=1, \ldots, k$ :

$v_{1}=\frac{\pi_{1}+\delta \pi_{2}+\cdots+\delta^{k-1} \pi_{k}}{1-\delta^{k}}, \quad v_{2}=\frac{\pi_{2}+\delta \pi_{3}+\cdots+\delta^{k-1} \pi_{1}}{1-\delta^{k}}, \ldots, \quad v_{k}=\frac{\pi_{k}+\delta \pi_{1}+\cdots+\delta^{k-1} \pi_{k-1}}{1-\delta^{k}}$,

Notice that

$$
v_{1}=\delta v_{2}+\pi_{1}, \quad v_{2}=\delta v_{3}+\pi_{2}, \ldots, \quad v_{k}=\delta v_{1}+\pi_{k} .
$$

Assign $p_{k}$ to be the lowest point in the firm's price sequence:

$$
p_{k}=\min _{s \in\{1, \ldots, k\}} p_{s}
$$

and let the cartel maximise $v$, defined as follows:

$$
v=\max \left\{v_{1}, \ldots, v_{k}\right\}
$$

With $v$ as the objective, assigning the minimum point of the cycle to position $k$ in the price sequence is without loss of generality. That is, it is equivalent to considering $v_{1}$ as the cartel objective and allowing the position of the minimum price to be unrestricted.

The cartel can craft the price path to manipulate the behaviour of the fringe. If the cartel price is high, the fringe firm undercuts and attracts customers away from the cartel. If the cartel price is low, the fringe relents and the cartel market share is higher. The tradeoff between cartel price and market share is then an important consideration for the cartel. We begin, in Section 4.1, by investigating equilibria in which the fringe firm never relents. We consider successive generalisations in subsequent sections. We first set up the cartel's problem with Lemma 2.

Lemma 2. For $k \leq m$, the optimal $k$-period cycle $\sigma^{(k)}$ consistent with market equilibrium is given by the solution to the following program:

$$
\max _{p_{1}, \ldots, p_{k} \in[0,1]} v
$$


subject to, for $s=1, \ldots, k-1$,

$$
\begin{aligned}
& p_{k}=0, \\
& v_{s} \geq \alpha_{1} p_{s}, \\
& v_{s} \geq \begin{cases}\alpha_{n} & \text { if the fringe undercuts, } \\
\alpha_{n-1} & \text { if the fringe relents. }\end{cases}
\end{aligned}
$$

The lemma defines the incentive constraints of the cartel. Because an undercutting firm captures the whole market in period $k$, it is not possible for the cartel to earn profits in period $k$. Setting $p_{k}=0$ establishes a minimum price of zero on the equilibrium path, and provides obfuscation support for all subsequent positive prices. The remaining constraints are sufficient to guarantee internal cartel discipline. For prescribed cartel price $p_{s}>p_{k}$, marginally undercutting delivers a market share of $\alpha_{1}$. The constraints in (14) deter this form of deviation. Alternatively, if consumers are sufficiently inattentive, it may be tempting to raise price to 1 and settle for a lower market share. This deviation is deterred by the constraints in (15). If the fringe firm undercuts the cartel price, then a deviator obtains a market share of $\alpha_{n}$ by relenting to a price of 1 . Alternatively, if the fringe relents, a deviator can marginally undercut the fringe firm and receive a market share of $\alpha_{n-1}$ at a price of approximately 1 .

For future reference, define the expected market share for a cartel member setting price $p_{t}$ when the fringe undercuts and relents, respectively, as

$$
\bar{\alpha}_{u}=\frac{1-\alpha_{1}}{n-1}, \quad \bar{\alpha}_{r}=\frac{1-\alpha_{n}}{n-1}
$$

and label the program (12) - (14) the Undercutting Program and the program (12) - (15) the Full Program. The Undercutting Program describes the problem faced by a cartel concerned only by deviations in which members undercut the cartel price. As we shall see, this program determines the shape of the optimal price path.

\subsection{An undercutting fringe}

In this section, we consider the cartel's problem when the fringe firm undercuts in every period except period $k$. We characterise the optimal path with Lemmas 3 and 4 . We first introduce the critical discount factor for a cartel guarding only against undercutting:

$$
\delta_{1}(\theta)=\left(\frac{\alpha_{1}-\bar{\alpha}_{u}}{\alpha_{1}}\right)^{(k-1) / k} .
$$


As we show in Lemma $3, \delta_{1}$ is the lowest discount factor consistent with collusive equilibrium with an undercutting fringe. The critical discount factor reflects the usual relationship between collusion, deviation, and punishment profits. If the fringe undercuts, in each period of a cycle other than $k$, cartel members obtain market share of $\bar{\alpha}_{u}$, and the optimal undercutting deviation yields a market share of $\alpha_{1}$. Recall also that a zero-value punishment is available. Finally, the power $(k-1) / k$ accounts for the fact that period $k$ of the cycle does not contribute to the incentive constraints of the cartel.

Lemma 3. Suppose, in a market equilibrium, the fringe undercuts in every period. Then the $k$-period cycle $\sigma^{(k)}$ solves the Undercutting Program if and only if $\delta \geq \delta_{1}$. The cycle is unique and has the following properties:

1. prices decline monotonically over the cycle: $p_{1} \geq p_{2} \geq \cdots>p_{k}$, with $p_{1}=1$ and $p_{k}=0$;

2. $p_{s}=\min \left\{1, \frac{\delta \alpha_{1}}{\alpha_{1}-\bar{\alpha}_{u}} p_{s+1}\right\}, s=1, \ldots, k-2$, and $p_{k-1}=\min \left\{1, \frac{\delta^{2} v_{1}}{\alpha_{1}-\bar{\alpha}_{u}}\right\}$; and all prices are increasing in $\delta$;

3. $v_{1} \geq v_{2} \geq \cdots \geq v_{k}$ and $v=v_{1}$ is an increasing function of $\delta$; and

4. $v_{s}=\min \left\{\bar{\alpha}_{u}+\delta v_{s+1}, \frac{\delta \alpha_{1}}{\alpha_{1}-\bar{\alpha}_{u}} v_{s+1}\right\}, s=1, \ldots, k-1$, and $v_{k}=\delta v_{1}$.

We offer the following definitions to aid our discussion of the lemma. For each "knot" discount factor, there is an incentive constraint that binds to the left, but not to the right.

Definition 3. The knot discount factor $\delta_{s}$ connects two regions: if $\delta<\delta_{s}$ the equilibrium path has $p_{s}<1$; if $\delta \geq \delta_{s}$ the equilibrium path has $p_{s}=1$, for $s=2, \ldots, k-1$.

Definition 4. 1. An equilibrium price path is a pure sales path if $p_{s}=1$ for $s=1, \ldots, k-1$.

2. An equilibrium price path is a distinct cycle path if $p_{s}<1$ for $s=2, \ldots, k-1$.

The solution has a similar structure to that of de Roos and Smirnov (forthcoming). A set of complementary slackness conditions govern the optimal price path. In each period, cartel members either set the monopoly price or decrease price according to Part 2 of the lemma. The knot discount factors $\delta_{s}$ demarcate paths with different depth and breadth of sales. For $\delta \in\left[\delta_{k-1}, 1\right]$, a pure sales path is observed. For $\delta \in\left[\delta_{1}, \delta_{2}\right)$, we see a distinct cycle path. In between these extremes, cycles involving more extended sales are observed for lower discount factors.

Lemma 4 completes our characterisation of the optimal path.

\section{Lemma 4.}


1. The knot discount factors $\delta_{s}, s \in\{2, \ldots, k-1\}$, are determined by

$$
\delta_{s}^{k}+\frac{\bar{\alpha}_{u}}{\alpha_{1}} \sum_{j=k-s+1}^{k-1} \delta_{s}^{j}=\left(\frac{\alpha_{1}-\bar{\alpha}_{u}}{\alpha_{1}}\right)^{k-s} .
$$

2. For $s=1, \ldots, k-1$, if $\delta \in\left[\delta_{s}, \delta_{s+1}\right)$, then a k-period cycle solving the Undercutting Program yields

$$
v_{1}=\frac{\left(1-\delta^{s}\right) \bar{\alpha}_{u}}{\left(1-\left(\frac{\alpha_{1}-\bar{\alpha}_{u}}{\alpha_{1}}\right)^{k-s-1} \delta^{k}\right)(1-\delta)} .
$$

Part 1 of the lemma describes the knot discount factors associated with the complementary slackness conditions of Lemma 3. Lemma 3 implies that the price path is completely determined by $v_{1}$. We solve explicitly for this in Part 2. This allows an analytic solution for the optimal price path and accompanying value of the cartel's objective function. We illustrate the optimal path with Example 2.

Example 2. There are $n=4$ firms consisting of three cartel members and one fringe firm. Cartel members choose strategies with cycle length $k=4$. The lowest priced firm obtains a market share $\alpha_{1}=0.4$, and the highest priced firm obtains share $\alpha_{4}=0.1$. With these parameter values, the fringe never relents and the relenting constraints in (15) do not bind for the cartel. Figure 1 displays the resulting equilibrium price path for a range of discount factors. The vertical axis shows price and the horizontal axis indexes discount factors. Reading the figure vertically reveals price in each period of a cycle for a given discount factor.

Sustainability of collusion depends on relative not absolute prices, so there is no benefit to lowering $p_{1}$ below the monopoly level. In period $k=4, p_{k}=0$. The remaining prices are determined by the discount factor. For sufficiently high $\delta$, monopoly pricing can be sustained in periods 2 and 3. For $\delta$ below the knot discount factor $\delta_{3}, p_{3}$ must be lowered in order to satisfy the undercutting constraints in (14). Similarly, for $\delta<\delta_{2}, p_{2}$ must be lowered to satisfy these constraints.

The shape of the optimal price path in Lemma 3 is determined by the undercutting constraints in (14) and not the relenting constraints in (15). This feature extends to solutions to the Full Program. In order to relax each undercutting constraint, the cartel must reduce prices along the path. This is in direct conflict with the cartel's objective function. The optimal price path is therefore determined by binding undercutting constraints. By contrast, raising prices relaxes the relenting constraints. Hence, there is no conflict between the objective function and the relenting constraints, and the optimal path is not shaped by these constraints. 
Figure 1: Optimal cartel prices by discount factor

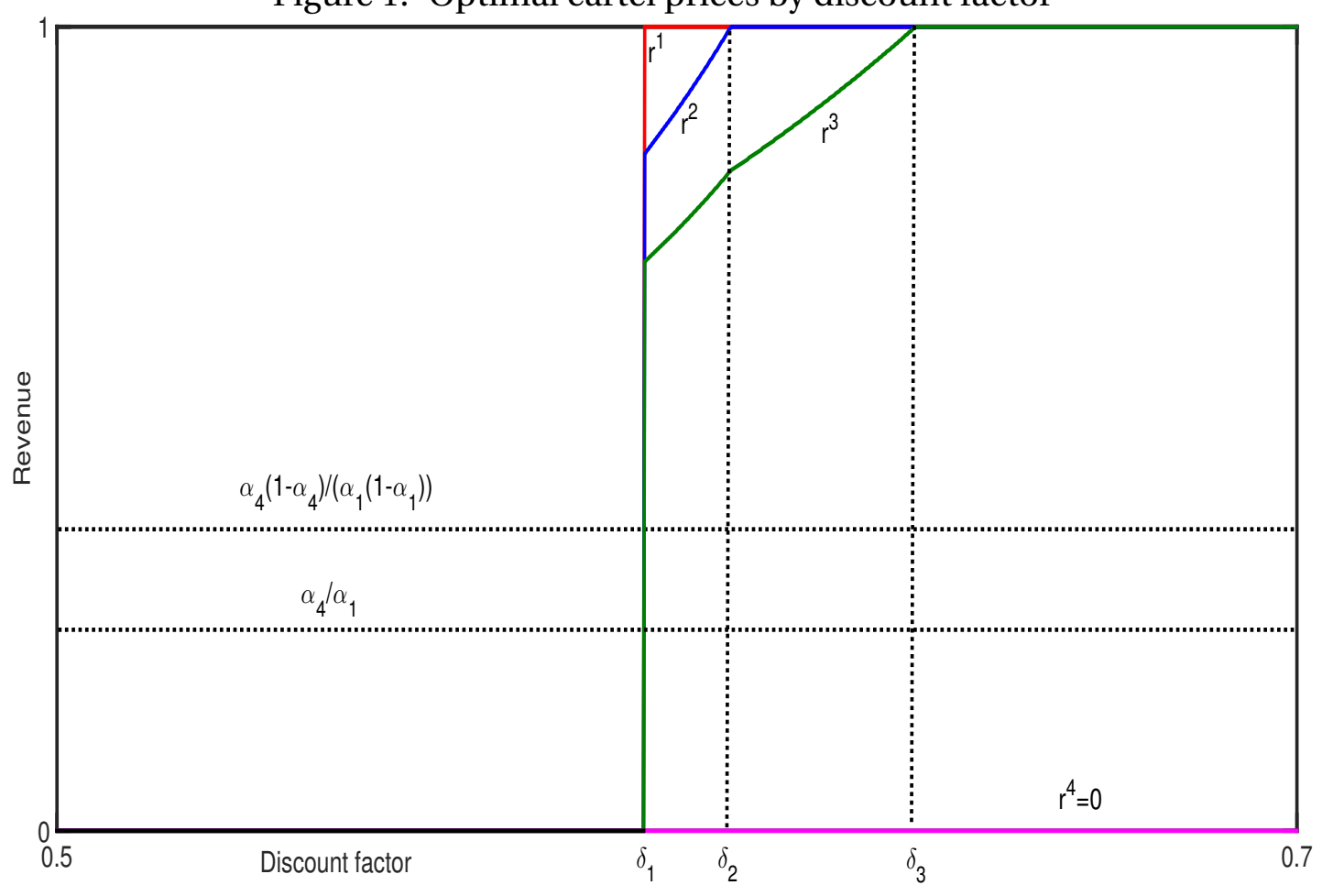

The only role of the relenting constraints is to determine the feasibility of the optimal path. Given the price path $\left\{p_{s}\right\}_{s=1}^{k}$, define the discount factor $\hat{\delta}(\theta)$ implicitly by

$$
v_{k-1}(\hat{\delta})=\alpha_{n},
$$

where $v_{k-1}$ is determined by (19) and (10). The discount factor $\hat{\delta}$ describes the vulnerability of the cartel to relenting deviations. In light of both undercutting and relenting constraints, the cartel's critical discount factor is given by $\delta^{*}=\max \left\{\delta_{1}, \hat{\delta}\right\}$. Because the price path is decreasing, the cartel is most vulnerable in period $k-1$. Using Lemma 3 , we can show that, when the fringe undercuts,

$$
p_{k-1}\left(\delta_{1}\right)=\left(\frac{\alpha_{1}-\bar{\alpha}_{u}}{\alpha_{1}}\right)^{(k-2) / k} \equiv \chi(\theta), \quad \quad p_{k-1}(\hat{\delta})=\frac{\alpha_{n}}{\alpha_{1}} .
$$

Lemma 5 then expresses the critical discount factor as a function of the parameter vector.

Lemma 5. Suppose the fringe undercuts in every period. Then the critical discount factor for the cartel is given by

$$
\delta^{*}(\theta)= \begin{cases}\delta_{1}(\theta) & \text { if } \chi \geq \alpha_{n} / \alpha_{1} \\ \hat{\delta}(\theta) & \text { if } \chi<\alpha_{n} / \alpha_{1}\end{cases}
$$




\subsection{Manipulation of the fringe}

In addition to the internal incentive constraints of cartel members, the cartel also manipulates the behaviour of the fringe. Until now, we have presumed that the fringe undercuts the cartel price in every period. Through Lemma 6 , we provide sufficient conditions for optimal equilibria with this property. In Example 3, we illustrate an equilibrium in which the cartel instead induces the fringe firm to relent in period $k-1$. We then consider the cartel's general problem. Proposition 1 describes the structure of the optimal price path for a cartel concerned with both internal incentive constraints and opportunities for fringe manipulation.

To introduce Lemma 6, we first explore the logic behind fringe manipulation. For any given cartel price, if the fringe firm relents rather than undercuts, then this increases the market share of the cartel, raising cartel profitability. However, the cartel may choose not to encourage the fringe to relent for two possible reasons. First, inducing the fringe to relent may require the cartel to set a lower price. Given cartel price $p_{s}$, the fringe firm prefers to relent in period $s$ if $p_{s} \leq \alpha_{n} / \alpha_{1}$. The cartel can induce the fringe to relent by setting $p_{s}=\alpha_{n} / \alpha_{1}$, yielding cartel member profits of $\pi_{s}=\bar{\alpha}_{r} \alpha_{n} / \alpha_{1}$. If the fringe instead undercuts, cartel members earn $\pi_{s}=\bar{\alpha}_{u} p_{s}$. Now, consider the price $p_{s}(\theta)$ that solves the Undercutting Program based on a fringe that always undercuts. There is a threshold price level of

$$
p_{s}(\theta)=\frac{\alpha_{n} \bar{\alpha}_{r}}{\alpha_{1} \bar{\alpha}_{u}}=\frac{\alpha_{n}\left(1-\alpha_{n}\right)}{\alpha_{1}\left(1-\alpha_{1}\right)} \equiv a,
$$

below which the cartel prefers to set the price $p_{s}=\alpha_{n} / \alpha_{1}$ and induce the fringe to relent, where $a \leq 1$.

Second, even if it is more profitable for the cartel to induce the fringe to relent, the cartel may not be sustainable in this case. To see this, consider the cartel's relenting constraints in (15). If the fringe relents, then a cartel member can obtain a market share of $\alpha_{n-1}$ instead of $\alpha_{n}$ by deviating to a price marginally below the fringe price of 1 . Therefore, the cartel may not be sustainable if the fringe firm relents. To consider this possibility, we introduce the term

$$
\eta=\frac{\alpha_{n-1}}{\alpha_{1}}
$$

Lemma 6. If $\left\{p_{s}\right\}_{s=1}^{k}$ solve the Undercutting Program when the fringe always undercuts, $\delta \geq$ $\delta^{*}$, and

$$
\max \{\eta, \chi\} \geq a,
$$

then $\left\{p_{s}\right\}_{s=1}^{k}$ form an optimal market equilibrium in which the fringe undercuts. 
Lemma 6 provides sufficient conditions on the parameters $\theta$ for market equilibria in which the fringe always undercuts the cartel price. In the following example we illustrate a market equilibrium which does not satisfy the conditions of Lemma 6 . The cartel optimally induces the fringe to relent in period $k-1$.

Example 3. Consider the following minor variation to Example 2. There are $n=4$ firms consisting of three cartel members and a fringe firm. Cartel members choose strategies with cycle length $k=4$. The lowest priced firm obtains a market share $\alpha_{1}=0.35$, and the highest priced firm obtains share $\alpha_{4}=0.2$. Figure 2 displays the resulting optimal equilibrium price path for a range of discount factors. The vertical axis shows price and the horizontal axis indexes discount factors. Reading the figure vertically reveals price in each period of a cycle for a given discount factor.

The only changes from Example 2 are a decrease in $\alpha_{1}$ from 0.4 to 0.35 and an increase in $\alpha_{4}$ from 0.1 to 0.2 . That is, consumers are less attentive. For discount factors above $\delta_{r}$, there is no qualitative difference to our earlier example. For discount factors above $\delta_{1}$ and below $\delta_{r}$, the optimal cartel price $p_{3}$ crosses the cut-off level $a=\alpha_{n}\left(1-\alpha_{n}\right) /\left(\alpha_{1}\left(1-\alpha_{1}\right)\right)$. The cartel then induces the fringe to relent by setting a price of $\alpha_{n} / \alpha_{1}$. Consequently, the fringe relents in period $k-1$ for discount factors between $\delta_{1}$ and $\delta_{r}$.

In Proposition 1 below, we provide a general characterisation of the optimal price path that allows for the possibility that the fringe either undercuts or relents. We show that the fringe manipulation problem reduces to a double cut-off rule: the cartel decides in which period the fringe firm should begin and finish relenting; and the fringe undercuts in all other periods. To set up the problem, we first construct a sequence of price paths, corresponding to alternative cut-off policies.

Let $\left\{p_{s}^{(0)}, v_{s}^{(0)}\right\}_{s=1}^{k}$ solve the Undercutting Program when the fringe always undercuts. In addition, define the sequence of cartel price vectors and associated cartel values $\left\{p_{s}^{(q, r)}, v_{s}^{(q, r)}\right\}_{s=1}^{k}$, for $q=2, \ldots, k-1$ and $r=q, \ldots, k-1$ as follows. For $q=2, \ldots, k-1$ and $r=k-1$, let

$$
p_{s}^{(q, r)}= \begin{cases}0 & \text { if } s=k, \\ \frac{\alpha_{n}}{\alpha_{1}} & \text { if } s=q, \ldots, k-1, \\ \min \left\{1, \frac{1}{\alpha_{1}}\left(\frac{\alpha_{1}-\bar{\alpha}_{u}}{\delta \alpha_{1}}\right)^{q-2} v_{1}^{(q, r)}\right\} & \text { if } s=q-1, \\ \min \left\{1, \frac{\delta \alpha_{1}}{\alpha_{1}-\bar{\alpha}_{u}} p_{s+1}^{(q, r)}\right\} & \text { if } s=2, \ldots, q-2, \\ 1 & \text { if } s=1 .\end{cases}
$$


Figure 2: Optimal cartel prices with fringe manipulation

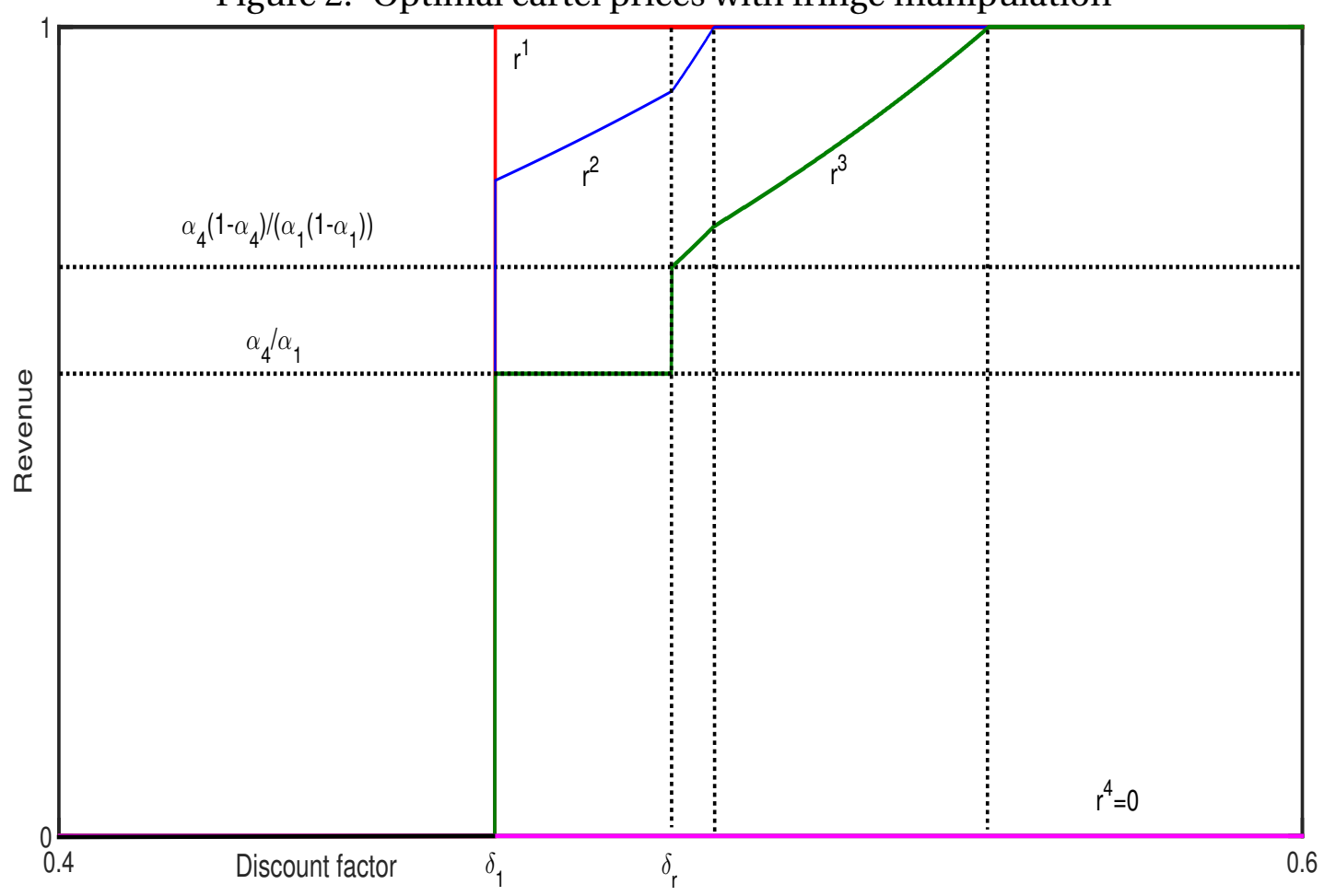

For $q=2, \ldots, k-1$ and $r=q, \ldots, k-2$, let

$$
p_{s}^{(q, r)}= \begin{cases}0 & \text { if } s=k, \\ \min \left\{1, \frac{\delta^{2} v_{1}^{(q, r)}}{\alpha_{1}-\bar{\alpha}_{u}}\right\} & \text { if } s=k-1, \\ \min \left\{1, \frac{\delta \alpha_{1}}{\alpha_{1}-\bar{\alpha}_{u}} p_{s+1}^{(q, r)}\right\} & \text { if } s=r+1, \ldots, k-2, \\ \frac{\alpha_{n}}{\alpha_{1}} & \text { if } s=q, \ldots, r, \\ \min \left\{1, \frac{1}{\alpha_{1}}\left(\frac{\alpha_{1}-\bar{\alpha}_{u}}{\delta \alpha_{1}}\right)^{q-2} v_{1}^{(q, r)}\right\} & \text { if } s=q-1, \\ \min \left\{1, \frac{\delta \alpha_{1}}{\alpha_{1}-\bar{\alpha}_{u}} p_{s+1}^{(q, r)}\right\} & \text { if } s=2, \ldots, q-2, \\ 1 & \text { if } s=1 .\end{cases}
$$

The path $\left\{p_{s}^{(0)}\right\}_{s=1}^{k}$ corresponds to the optimal cartel price path when the fringe firm never relents. This is the solution we described in Section 4.1. The path $\left\{p_{s}^{(q, r)}\right\}_{s=1}^{k}$ describes the optimal price path when the fringe firm relents in the $r-q+1$ consecutive periods from $q \in$ $\{2, \ldots, k-1\}$ to $r \in\{q, \ldots, k-1\}$. In addition, let $\left\{v_{s}^{(q, r)}\right\}_{s=1}^{k}$ be the associated cartel continuation values.

Because cartel incentives depend only on relative prices, the cartel will always optimally set a price of 1 in period 1 . If in period $s$, for $1<s<k$, the cartel wishes to encourage the 
fringe to relent, it will set the price $p_{s}=\alpha_{n} / \alpha_{1}$ that is just sufficient to induce relenting. In the remaining periods, $s=2, \ldots, q-1$ and $s=r+1, \ldots, k-2$, optimal prices are determined by complementary slackness conditions that resemble the solution for the undercutting fringe detailed in Lemma 3.

Next, we define the corresponding fringe policies. Let $b_{s}^{(0)}=\tilde{p}_{s}^{(0)}, s=1, \ldots, k-1$, and $b_{k}^{(0)}=0$; and define the sequence of price vectors $\left\{b_{s}^{(q, r)}\right\}_{s=1}^{k}, q=2, \ldots, k-1$ and $r=q, \ldots, k-1$ as follows:

$$
b_{s}^{(q, r)}= \begin{cases}1 & \text { if } s \in\{q, \ldots, r\} \\ 0 & \text { if } s=k, \\ \dot{p}_{s}^{(q, r)} & \text { otherwise }\end{cases}
$$

We are now in a position to state our main result. Proposition 1 provides the conditions required for equilibrium, introduces the double cut-off rule used to evaluate whether the cartel encourages the fringe firm to undercut or relent, and describes the cartel's optimal price path.

Proposition 1. Label $\left\{p_{s}, b_{s}, v_{s}\right\}_{s=1}^{k}$ as a candidate solution to the Full Program and assign $\left\{p_{s}, b_{s}, v_{s}\right\}_{s=1}^{k}$ as follows:

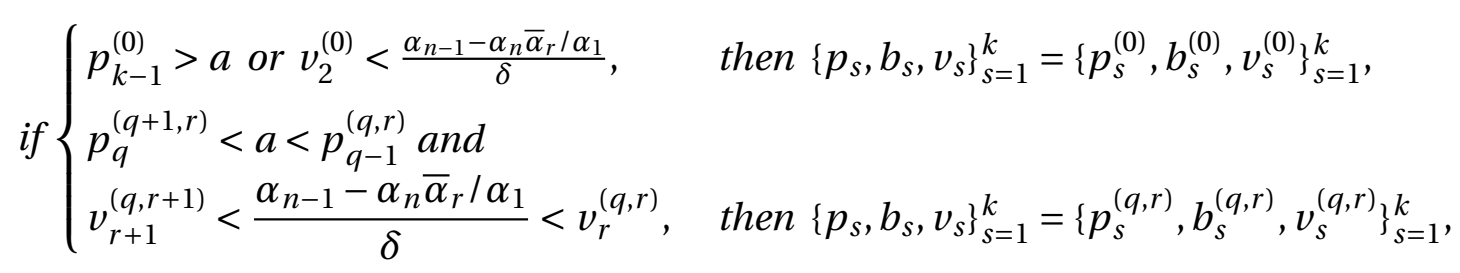

where $a$ is defined in (23), $p_{s}^{(0)}$ and $v_{s}^{(0)}$ are defined in Lemma $3, p_{s}^{(q, r)}$ is defined in (25) and (26), $v_{s}^{(q, r)}$ are corresponding values, and $b_{s}^{(q, r)}$ is defined in (27), where $q=2, \ldots, k-1$ and $r=q, \ldots, k-1$.

If $v_{1} \geq \alpha_{1}$ and $v_{k-1} \geq \alpha_{n}$, then $\left\{p_{s}, b_{s}, v_{s}\right\}_{s=1}^{k}$ is the optimal market equilibrium for the cartel. Otherwise, there is no market equilibrium with positive value for the cartel.

Proposition 1 describes an inductive structure. $\left\{p_{s}^{(0)}, b_{s}^{(0)}, v_{s}^{(0)}\right\}_{s=1}^{k}$ represent the optimal price and value paths when the fringe firm always undercuts, as described in Section 4.1. If $p_{k-1}^{(0)}>a$, then the cartel prefers the fringe firm to undercut in period $k-1$, and $\left\{p_{s}^{(0)}\right\}_{s=1}^{k}$ is indeed the optimal price path. Alternatively, if $v_{2}^{(0)}<\frac{\alpha_{n-1}-\alpha_{n} \bar{\alpha}_{r} / \alpha_{1}}{\delta}$ then the cartel has to avoid encouraging the fringe to relent, because this will lead to a violation of the cartel's own relenting constraints, and $\left\{p_{s}^{(0)}\right\}_{s=1}^{k}$ is again the optimal feasible price path.

On the other hand, if the cartel prefers the fringe firm to relent and it is feasible, then we consider the sequence $\left\{p_{s}^{(q, r)}, b_{s}^{(q, r)}, v_{s}^{(q, r)}\right\}_{s=1}^{k}$. If $p_{q}^{(q+1, r)}<a<p_{q-1}^{(q, r)}$ and $v_{r+1}^{(q, r+1)}<\left(\alpha_{n-1}-\right.$ 
$\left.\alpha_{n} \bar{\alpha}_{r} / \alpha_{1}\right) / \delta<v_{r}^{(q, r)}$, then the fringe firm relents in periods $q, \ldots, r$, and $\left\{p_{s}^{(q, r)}\right\}_{s=1}^{k}$ is feasible and optimal. We apply this double cut-off rule recursively to obtain the optimal price path.

The sustainability of the optimal price path depends on two final conditions. The constraint $v_{1} \geq \alpha_{1}$ is the analogue of the critical undercutting discount factor, $\delta_{1}$. Constraints in (14) outside the double cut-off region $\{q, \ldots, r\}$ can be negotiated by adjusting relative prices. If the undercutting constraint in period 1 is not satisfied, relative prices cannot be further adjusted and the cartel is unsustainable. If the second cut-off period $r<k-1$, the constraint $v_{k-1} \geq \alpha_{n}$ corresponds to the critical discount factor based on the cartel's relenting constraints, $\hat{\delta}$. When $r=k-1$ this constraint is satisfied automatically.

The double cut-off rule of Proposition 1 can lead to prices that are not monotonic in the discount factor, as illustrated by Example 4.

Example 4. Consider the following variation to Example 2. There are $n=4$ firms consisting of three cartel members and a single fringe. Cartel members choose strategies with cycle length $k=4$. The firms obtain the following market shares $\alpha_{1}=0.32, \alpha_{2}=0.25, \alpha_{3}=0.23$ and $\alpha_{4}=0.2$. Figure 3 displays the resulting optimal equilibrium price path for a range of discount factors. The vertical axis shows price and the horizontal axis indexes discount factors. Reading the figure vertically reveals the cartel price in each period of a cycle for a given discount factor.

For discount factors above $\delta_{r}$, the path has the same qualitative features as Example 2 . For $\delta<\delta_{r}$, the cartel would prefer the fringe to relent, and for discount factors in the range $\delta_{u} \leq \delta<\delta_{r}$, the cartel sets the price $\alpha_{n} / \alpha_{1}$ in order to induce the fringe to relent. However, for discount factors below $\delta_{u}$, while the cartel would prefer the fringe to relent, the cartel's incentive constraints are violated if the fringe does in fact relent. Therefore, for the range $\delta<$ $\delta_{u}$, the fringe undercuts, and the cartel sets an optimal price conditional on an undercutting fringe.

Corollary 1 provides sufficient conditions for a monotonic relationship between prices and the discount factor, as illustrated by Examples 2 and 3. Under the conditions of the corollary, the cartel's relenting incentive constraints are always satisfied when the cartel induces the fringe to relent. To set up the corollary, we first define the critical discount factors $\delta^{\prime}$ and, implicitly, $\delta_{1}^{(q)}$ as follows:

$$
\begin{aligned}
\delta^{\prime} & =\left(\frac{\alpha_{n-1}}{\alpha_{1}}-\frac{\alpha_{n} \bar{\alpha}_{r}}{\alpha_{1}^{2}}\right)^{1 / 2}, \\
\delta_{1}^{k}+\frac{\alpha_{n} \bar{\alpha}_{r}}{\alpha_{1}^{2}} \sum_{u=q-1}^{k-2} \delta_{1}^{u} & =\left(\frac{\alpha_{1}-\bar{\alpha}_{u}}{\alpha_{1}}\right)^{q-1} .
\end{aligned}
$$


Figure 3: A non-monotonic relationship between prices and patience

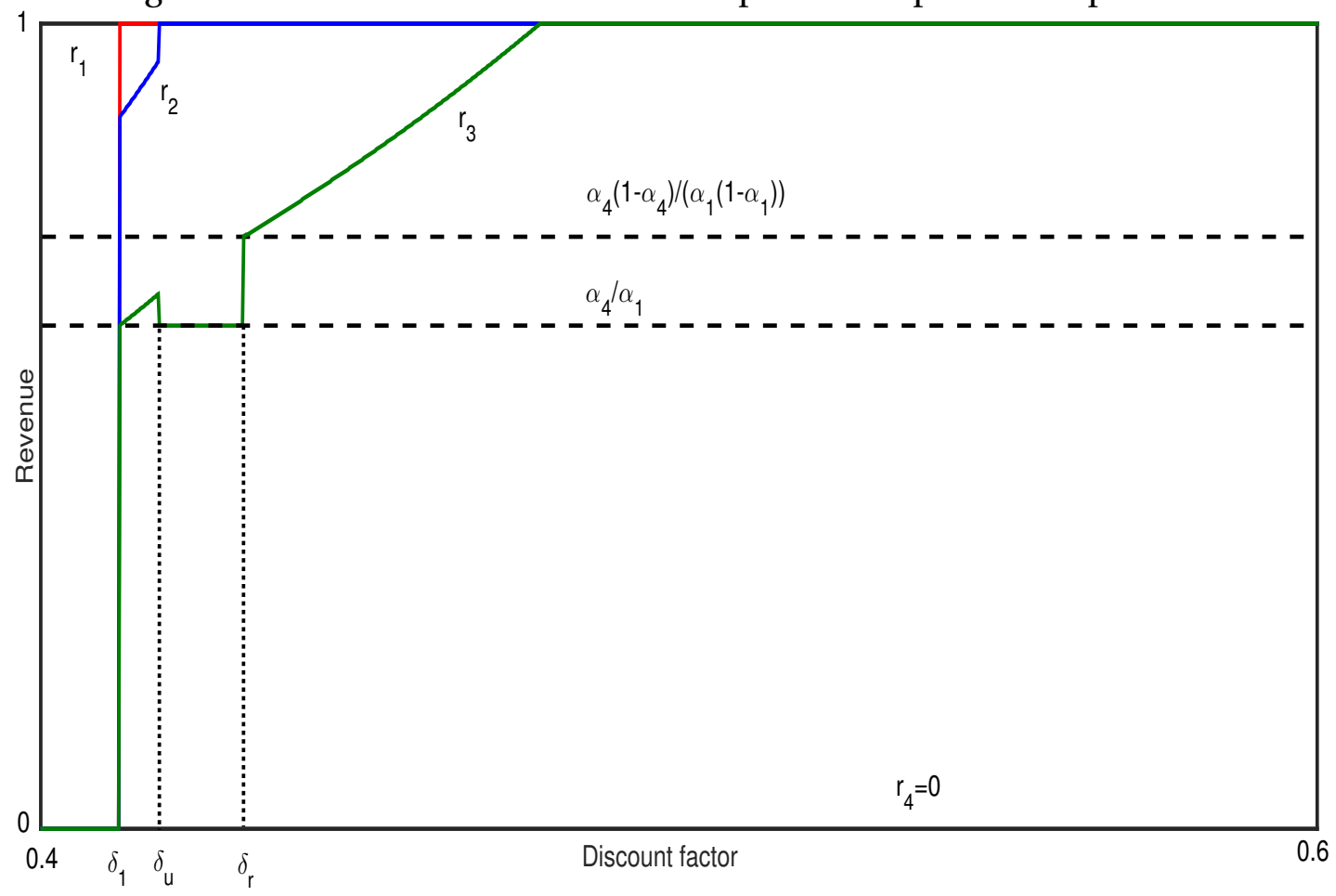

Corollary 1. When $\delta^{\prime} \leq \delta_{1}^{(q)}$, the k-period cycle $\sigma^{(k)}$ that solves the Full Program is unique, prices and values decline monotonically over the cycle, $v=v_{1}$ is an increasing function of $\delta$, and prices decrease monotonically with $\delta$.

At the critical discount factor $\delta_{1}^{(q)}$, the cartel's undercutting incentive constraints in (14) are binding along the path in which the fringe relents in periods $q$ to $k-1$. At the discount factor $\delta^{\prime}$, the temptation to deviate by undercutting is equal to the temptation to deviate by relenting. Thus, for $\delta^{\prime} \leq \delta_{1}^{(q)}$, if it is desirable for the cartel to encourage the fringe to relent, then it is always feasible. This rules out non-monotonic relationships such as the one illustrated in Figure 3.

Lemma 7 completes our characterisation of the optimal price path by expressing the critical discount factor as a function of the parameter vector. We use the notation $\delta_{1}^{(0)}$ and $\delta_{1}^{(q, r)}$ to refer to the critical discount factor based on the cartel's undercutting constraints, with an undercutting fringe and a fringe that is manipulated into relenting in periods between $q$ and $r$, respectively. We then assign the discount factor $\delta_{1}(\theta)$ according to the solution outlined in Proposition 1. Equation (17) defines $\delta_{1}^{(0)}$ explicitly for the case of an undercutting fringe. For $q \leq k-1$ and $r=k-1, \delta_{1}^{(q, r)}$ is defined by equation (29), while for $q \leq r$ and $r<k-1, \delta_{1}^{(q, r)}$ is 
defined implicitly by

$$
\delta_{1}^{k}\left(\frac{\alpha_{1}-\bar{\alpha}_{u}}{\alpha_{1}}\right)^{r-k}+\frac{\alpha_{n} \bar{\alpha}_{r}}{\alpha_{1}^{2}} \sum_{u=q-1}^{r-2} \delta_{1}^{u}=\left(\frac{\alpha_{1}-\bar{\alpha}_{u}}{\alpha_{1}}\right)^{q-1} .
$$

Because the value of the cartel decreases over the cycle, the cartel is most vulnerable to a relenting deviation in period $k-1$. If the fringe undercuts in period $k-1$,

$$
p_{k-1}\left(\delta_{1}\right)=\frac{\delta_{1}^{2} \alpha_{1}}{\alpha_{1}-\bar{\alpha}_{u}} \equiv \chi(\theta), \quad \quad p_{k-1}(\hat{\delta})=\frac{\alpha_{n}}{\alpha_{1}} .
$$

In light of both undercutting and relenting constraints, the cartel's critical discount factor is given by $\delta^{*}=\max \left\{\delta_{1}, \hat{\delta}\right\}$. We formalise this result below.

Lemma 7. The critical discount factor for the cartel is given by

$$
\delta^{*}(\theta)= \begin{cases}\delta_{1}(\theta) & \text { if } r=k-1 \text { or } \chi \geq \alpha_{n} / \alpha_{1} \\ \hat{\delta}(\theta) & \text { otherwise. }\end{cases}
$$

We close this section with the following result, establishing that the cartel is easier to sustain with a cyclical price path relative to a constant price.

Corollary 2. There exists a time-varying price path with higher value than the optimal fixedprice path.

\subsection{Cycle complexity}

Equilibrium is determined by the set of parameters $(n, k, \delta, \beta)$. Of these parameters, the number of firms, their patience, and consumer attentiveness might be beyond the complete control of the cartel. However, the length of the cycle may be a choice variable, and we examine this choice in the next Proposition.

Proposition 2. The optimal $k$ period cycle always dominates any cycle with less periods.

Firms prefer a longer price sequence because it affords the flexibility to have a more profitable initial phase in each sequence, while maintaining a substantial range of prices to dampen the powers of observation of consumers. By increasing the value of the cartel, a longer price path relaxes the incentive compatibility constraints, making collusion sustainable for a greater range of discount factors.

Two factors might limit the length of price sequences. First, longer paths may be more complex in the sense that they require coordination on a greater number of prices. If coordination is costly, we might then expect the trade-off between complexity and profitability to yield an optimal finite cycle length. Second, finite consumer memory restricts the optimal length of price sequences. We explore this issue in the following section. 


\subsection{Finite memory}

Definition 2 imposes cyclical strategies on the cartel. In de Roos and Smirnov (forthcoming), we show, in a related context, that cyclical strategies are optimal when consumer memory is finite. In particular, we show that optimal cartel strategies are cyclical of length $m+1$, where $m$ is the length of consumer memory. The same argument applies here, and optimal strategies are described by Proposition 1.

The intuition behind this result is as follows. Because consumers have finite memory, the cartel must periodically set low supporting prices to ensure that consumers have recent experience with low prices. Supporting prices provide obfuscation protection for the remaining prices on the path, thereby relaxing the cartel's incentive constraints and allowing the cartel to set higher prices. The cartel's undercutting constraints dictate the shape of the optimal path, leading to a decreasing trajectory of prices between supporting prices as in Proposition 1.

\section{Discussion}

In this section, we discuss comparative statics and robustness exercises. In Section 5.1, we examine comparative statics with respect to consumer attentiveness. In Section 5.2, we examine the implications if the cartel faces more than one fringe competitor.

\subsection{Comparative statics}

In our model, the two sources of vulnerability for the cartel are member deviations and fringe competition. Both sources are affected by consumer attentiveness. If consumers are more attentive, member deviations involving undercutting are more effective, while those involving relenting are less profitable. At the same time, greater consumer attentiveness makes the cartel more vulnerable to undercutting by the fringe. In this section, we discuss the limiting cases of extreme consumer attentiveness and inattentiveness.

\subsubsection{Highly attentive consumers}

We first examine the limiting case as consumers become perfectly attentive.

Remark 1. When $\alpha_{1} \rightarrow 1$, the fringe always undercuts, the critical discount factor is $\delta_{1}$, and equilibrium with an undercutting fringe exists for a range $\delta \in\left[\delta_{1}, 1\right]$, where $\delta_{1} \rightarrow 1$. 
With high consumer attentiveness, the cartel is sensitive to both internal deviation and fringe undercutting. To induce the fringe to relent requires a substantial cartel price cut, and the cartel prefers to allow the fringe to undercut. To see that the fringe undercuts, observe from (21) that the price $p_{k-1}=\chi$ approaches 1 as $\alpha_{1}$ approaches 1 ; and observe from (23) that the threshold price $a$ approaches a level $\tilde{a} \leq 1 /(n-1)$. If follows from Lemma 6 that the cartel prefers to induce the fringe to undercut. With an undercutting fringe and perfectly attentive consumers, the fringe is able to capture most of the market and the profitability of the cartel drops. This raises the temptation of cartel members to deviate by undercutting the cartel and fringe, and the critical discount factor $\delta_{1}$ approaches 1.

Remark 1 implies that, as consumers become hyperattentive, we approach the extreme case of Bertrand price competition in which profitable collusion is impossible. Further, because the fringe undercuts and consumers are attentive, the fringe captures almost the entire market - the fringe is much more profitable than each cartel member.

\subsubsection{Perfect inattention}

We next examine the opposite extreme as consumers become perfectly inattentive.

Remark 2. As $\alpha_{1} \rightarrow 1 / n$, a pure sales equilibrium exists for any $\delta \geq \delta^{*} \rightarrow 0$. The cartel sets the monopoly price in periods $1, \ldots, k-1$ periods, and $p_{k}=0$.

As $\alpha_{1} \rightarrow 1 / n$, all market shares $\alpha_{1}, \ldots, \alpha_{n}$ approach $1 / n$. There is no incentive to deviate: undercutting is not profitable because it does not deliver an appreciable gain in market share, and relenting is not feasible because the cartel sets the monopoly price. Notice however, that the obfuscation role played by the period $k$ price $p_{k}=0$ is vital. This ensures both that an undercutting deviation does not trigger the attention of consumers, and that the fringe is unable to capture the entire market by deviating below $p_{k}$.

The typical context of a fringe firm operating alongside a cartel poses a puzzle. A fringe firm can free ride on the cartel, earning higher profits than cartel members. Which firm is privileged with the position of fringe status? With inattentive consumers, the payoffs obtained by cartel members and the fringe firm converge. As the free-riding benefit to being a fringe firm evaporates, this puzzle is ameliorated.

\subsection{Multiple fringe firms}

So far we have considered a cartel facing a single strategic fringe firm. In this section, we illustrate that our principal argument generalises to more than one fringe competitor. In 
Sections 5.2.1 and 5.2.2, we consider equilibria in which the fringe plays mixed and pure strategies, respectively.

\subsubsection{Mixed strategies for the fringe}

Lemma 8 characterises fringe behaviour when there are $f>1$ fringe firms. We discuss the lemma through Example 5. We use the notation $G^{u}$ to indicate the distribution of prices for fringe firms that undercut the cartel price, and $G^{r}$ to indicate the price distribution for relenting fringe firms. Define the distributions $G^{u}\left(p \mid p_{t}\right)$ and $G^{r}(p)$ implicitly by, respectively,

$$
\begin{gathered}
p \sum_{i=0}^{f-1}\left(\begin{array}{c}
f-1 \\
i
\end{array}\right) G^{u}\left(p \mid p_{t}\right)^{i}\left(1-G^{u}\left(p \mid p_{t}\right)\right)^{f-i-1} \alpha_{i+1}=\alpha_{f} p_{t}, \\
p \sum_{i=0}^{f-1}\left(\begin{array}{c}
f-1 \\
i
\end{array}\right) G^{r}(p)^{i}\left(1-G^{r}(p)\right)^{f-i-1} \alpha_{i+n-f+1}=\alpha_{n} .
\end{gathered}
$$

Lemma 8. Suppose $f>1, y_{t}=0$, and the cartel price in period $t$ is $p_{t}$ in a market equilibrium. Then, fringe firms play according to the cdf $G(p)$. If $p_{t} \geq \alpha_{n} / \alpha_{f}$, then $G(p)=G^{u}\left(p \mid p_{t}\right)$ and has support $\left[\alpha_{f} p_{t} / \alpha_{1}, p_{t}\right)$. If $p_{t} \leq \alpha_{n} / \alpha_{1}$, then $G(p)=G^{r}(p)$ and has support $\left[\alpha_{n} / \alpha_{n-f+1}, 1\right]$. If $p_{t} \in\left(\alpha_{n} / \alpha_{1}, \alpha_{n} / \alpha_{f}\right)$, then $G$ has support $\left[\alpha_{n} / \alpha_{1}, p_{t}\right) \cup[\widetilde{p}, 1]$, where $\widetilde{p}$ is defined implicitly by $G^{u}\left(p_{t} \mid \alpha_{n} / \alpha_{f}\right)=G^{r}(\widetilde{p})$, and

$$
G(p)= \begin{cases}G^{u}\left(p \mid \alpha_{n} / \alpha_{f}\right) & \text { if } p \in\left[\alpha_{n} / \alpha_{1}, p_{t}\right), \\ G^{r}(p) & \text { if } p \in[\widetilde{p}, 1] .\end{cases}
$$

Example 5. The market consists of $f=2$ fringe firms and $n=4$ firms in total. Market shares are given by $\left(\alpha_{1}, \alpha_{2}, \alpha_{3}, \alpha_{4}\right)=(0.4,0.3,0.2,0.1)$. Figure 4 depicts fringe strategies for a range of cartel prices, $p_{t}$. For $p_{t} \leq \alpha_{n} / \alpha_{1}=1 / 4$, fringe firms always relent and the distribution of fringe prices is given by the solid blue line labelled $G^{r}(p)$ with support $[1 / 2,1]$. If $p_{t} \geq \alpha_{n} / \alpha_{f}=1 / 3$, then the fringe undercuts with a price distribution that depends on $p_{t}$. The red solid line labelled $G^{u}\left(p \mid p_{t}=4 / 9\right)$ illustrates for the cartel price $p_{t}=4 / 9$. For $p_{t} \in(1 / 4,1 / 3)$, the fringe undercuts and relents with positive probability. The dashed black line illustrates when the cartel price is $p_{t}=0.3$. The fringe price distribution combines elements of the "relenting" distribution $G^{r}(p)$ and the "undercutting" distribution at the threshold price, $G^{u}\left(p \mid p_{t}=\alpha_{n} / \alpha_{f}\right)$.

Given the fringe policies described in Lemma 8, Lemma 9 describes the cartel's optimal pricing problem. 
Figure 4: Fringe price distribution

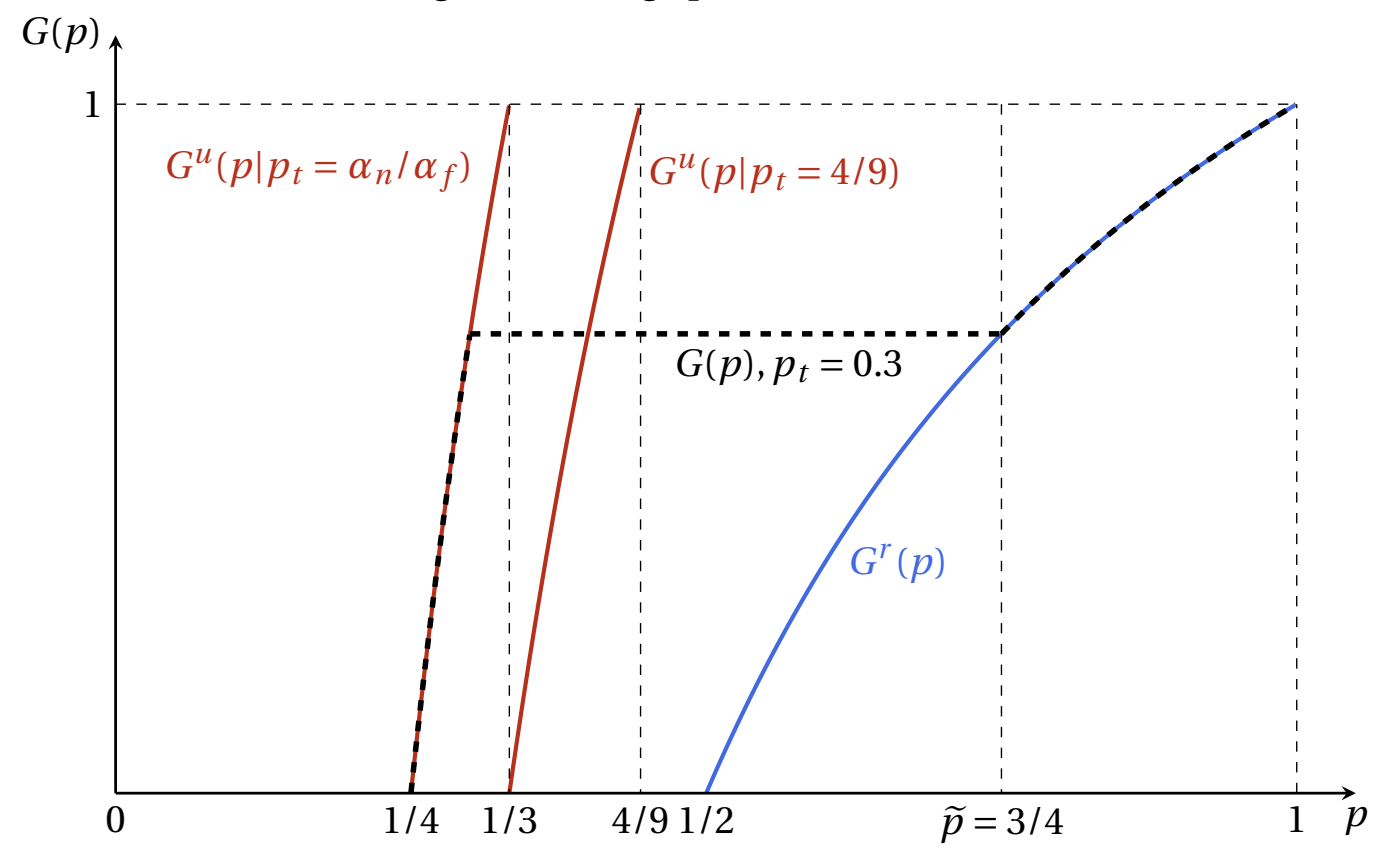

Lemma 9. The optimal $k$-period cycle $\sigma^{(k)}$ consistent with market equilibrium is given by the solution to the following program:

$$
\max _{p_{1} \ldots p_{k} \in[0,1]} v
$$

subject to, for $s=1, \ldots, k-1$,

$$
\begin{aligned}
& p_{k}=0 \\
& v_{s} \geq \begin{cases}\alpha_{f} p_{s} & \text { iffringe firms undercut } \\
\alpha_{1} p_{s} & \text { iffringe firms relent, }\end{cases} \\
& v_{s} \geq \begin{cases}\alpha_{n} & \text { iffringe firms undercut } \\
\alpha_{n} \frac{\alpha_{n-f}}{\alpha_{n-f+1}} & \text { iffringe firms relent. }\end{cases}
\end{aligned}
$$

The proof of Lemma 9 follows the same development as Lemma 2, and is omitted. Comparison with Lemma 2 reveals that the cartel's problem is very similar in the presence of multiple fringe firms. There are two principal differences. First, in the event that the fringe firms undercut, a cartel member seeking to deviate by undercutting must either undercut to a lower price in order to also guarantee a price below the fringe, or be satisfied with a market 
share of $\alpha_{f}$ instead of $\alpha_{1}$. Second, if the fringe firms relent, a cartel member contemplating a relenting deviation will now obtain a different market share because of the presence of relenting fringe firms.

Equilibrium cartel policies are qualitatively similar to those described in Proposition 1, and we omit a full statement.

\subsubsection{Pure strategies for the fringe}

The existence of equilibrium with pure strategies for the fringe requires restrictive conditions on market shares. For illustration, suppose there are two fringe firms. In equilibrium, each fringe firm must set a different price; otherwise, there would be an incentive to marginally undercut the price of one's fringe competitor. It follows that one of the fringe firms sets a price above the cartel, while the other firm sets a price marginally below the cartel price. In particular, given cartel price $p^{s}$ and Assumption 1, this means that the fringe prices must be 1 and $\hat{p}^{s}$. In equilibrium, there must be no incentive for each fringe firm to undercut the price of their fringe competitor, leading to two conditions. To ensure the high-priced fringe firm has no incentive to undercut her competitor requires $\alpha_{n} \geq \alpha_{1} p_{s}$. Similarly, we must have $\alpha_{1} p_{s} \geq \alpha_{n-1}$ to remove the incentive for the low-priced fringe firm to undercut her competitor. Combining these conditions, we must have $\alpha_{n-1}=\alpha_{n}$.

The following example illustrates an equilibrium in which two fringe firms adopt pure strategies.

Example 6. There are $n$ firms consisting of $n-2$ cartel members and two fringe firms. Suppose that $\alpha_{n-1}=\alpha_{n}$ and cartel members choose strategies with cycle length $k$. In each period $s$ with $p_{s}>p_{k}$, to prevent fringe deviation requires $\alpha_{n}=\alpha_{1} p_{s}$. In period $k$, we must have $p_{k}=0$. These conditions pin down the cartel price path with $p_{k}=0$ and $p_{s}=\alpha_{n} / \alpha_{1}$ for $s=1, \ldots, k-1$. This price path is sustainable for $\delta \geq \delta^{*}$ with $\delta^{*}<1$. Figure 6 illustrates equilibrium cartel and fringe pricing over time for the case $k=4, \alpha_{1}=0.35$, and $\alpha_{n-1}=\alpha_{n}=0.2$. The solid black line in the middle indicates the cyclical cartel price. The blue line at the top of the figure shows the price of the relenting fringe firm, and the red line just below the cartel price illustrates the undercutting fringe firm price. For visual clarity, we have exaggerated the distance between the cartel price and the undercutting fringe price.

\section{Conclusion}

In this paper, we examined the problem faced by a price-setting cartel negotiating a fringe competitor in the presence of imperfectly attentive consumers, where the consumer atten- 
Figure 5: Price paths with two fringe firms

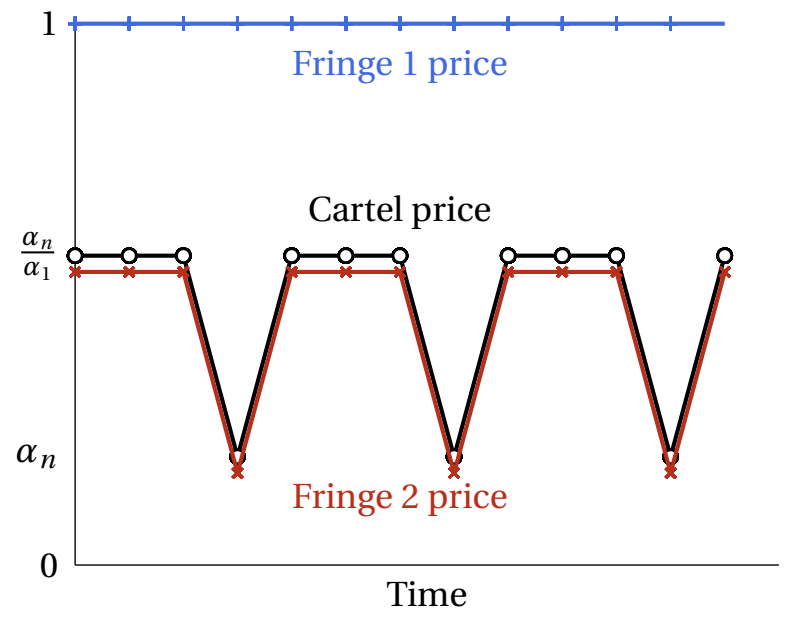

tion process depends on the current price vector relative to recent prices. Because each firm produces an identical product, the cartel is vulnerable to price undercutting by the fringe. Price dispersion then becomes a critical tool for the cartel. With fixed prices, undercutting by the fringe captures the attention of consumers, and the fringe is able to severely restrict the cartel. A dispersed price path hampers consumer price comparison and mitigates the market share gains of an aggressive fringe, permitting the survival of a profitable cartel.

We characterise the optimal price path of the cartel. The cartel must navigate both the internal incentive constraints of members and the impulses of the fringe. The optimal path is cyclical, involving a sequence of monopoly prices, punctuated with sales. Longer and deeper sales are required to satisfy internal incentive constraints if cartel members are less patient. The cartel manipulates the fringe through the use of a double cut-off rule. The cartel allows the fringe to undercut the price of the cartel in the early and latter stages of a cycle. In the intermediate stages of a cycle, the cartel may prefer to coax the fringe into relenting by raising price above the cartel. 


\section{Appendices}

\section{A Proofs}

\section{Lemma 1}

Suppose $y_{1}=1$. Let us consider a fixed price cartel in which all cartel members set the price $p_{t}=p>0$ for all $t$. Denote the fringe price in period $t$ by $p_{t}^{f}$. If $y_{t} \geq p$, then the fringe firm will undercut the cartel price and capture the entire market by setting $p_{t}^{f}=\dot{p}$. If instead $y_{t}<p$, then note that the fringe will choose a price $p_{t}^{f} \geq y_{t}$. Combining these observations, we must have $y_{t} \geq \dot{p}$.

Suppose $p>\alpha_{n}$. The fringe can earn profits of approximately $p$ by undercutting and profits of $\alpha_{n}$ by relenting to a price of 1 . The fringe therefore undercuts, and the cartel earns no profits in any time period. Cartel members therefore have an incentive to deviate by setting a price below $p$, leading to a contradiction. We therefore conclude that $p \leq \alpha_{n}$.

If $p \leq \alpha_{n}$, then the best response of the fringe firm is

$$
p^{f}= \begin{cases}\dot{p} & \text { if } y_{t} \geq p \\ 1 & \text { if } y_{t}<p\end{cases}
$$

Thus, in the initial period, with $y_{1}=1$, the fringe sets $p_{t}^{f}=\dot{p}$. For the next $m$ periods, the price $\dot{p}$ remains in consumer memory, so $y_{t}=\dot{p}$, and $p_{t}^{f}=1$. Every $m+1$ periods, the price $\hat{p}$ is no longer in memory, and instead $y_{t}=1$. Therefore, the fringe again undercuts with $p_{t}^{f}=\dot{p}$.

In the initial period, the value to each cartel member is given by $v_{1}=\frac{\delta p\left(1-\alpha_{n}\right)}{(n-1)(1-\delta)} D$, where $D=\frac{1-\delta^{m}}{1-\delta^{m+1}}$; while in the second period, the value to each cartel member is given by $v_{2}=$ $\nu_{1} / \delta$. By marginally undercutting the cartel price in the initial period, a deviator could obtain profits of approximately $p$ before punishment takes place. Alternatively, by relenting to just below the fringe price of 1 in the second period, a deviator could obtain profits of $\alpha_{n-1}$. Collusion is therefore sustainable if $v_{1} \geq \max \left[\alpha_{n-1}, p / \delta\right]$ or

$$
\delta \geq \max \left(\frac{n-1}{n-1+\left(1-\alpha_{n}\right) D}, 1-\frac{p\left(1-\alpha_{n}\right) D}{\alpha_{n-1}(n-1)}\right), \quad D=\frac{1-\delta^{m}}{1-\delta^{m+1}}
$$

\section{Lemma 2}

1. We first establish that infinite reversion to marginal cost pricing is an optimal penal code. Consider the stage game of our model consisting of a single period of play. Assumption 1 
implies that there exists a Nash equilibrium to the stage game in which each firm sets a price of zero. This is because any firm $j$ setting price $p^{j}>0$ will obtain market share of zero if her competitors set a price of zero. Therefore, infinite reversion to marginal cost pricing is an optimal penal code.

2. A standard application of the one-shot deviation principle is possible. See, for example, Fudenberg and Tirole (1991). We restrict attention to one-shot deviations below.

3. Next we show that $p_{k}=0$. Suppose otherwise that $p_{k}>0$. Because $y=p_{k}$, fringe firms always undercut $p_{k}$, and cartel members earn no profits in period $k$. The cartel therefore has an incentive to lower $p_{k}$, leading to a contradiction.

4. If a cartel member deviates by choosing a price $p \in\left(p_{k}, p_{s}\right)$ in period $s \neq k$, she obtains profit $\alpha_{1} p_{s}$. Deterring this deviation requires

$$
v_{s} \geq \alpha_{1} p_{s}, \quad s=1, \ldots, k .
$$

5. An alternative deviation for cartel members is to raise price above $p_{s}$. The optimal such deviation involves $p=1$. To prevent this deviation requires

$$
v_{s} \geq \alpha_{n}, \quad s=1, \ldots, k \text {. }
$$

This proves the lemma.

\section{Lemma 3}

1. Number the constraints in (14) $1, \ldots, k-1$, where constraint $s$ involves $v_{s}$.

2. Let us assume that $\delta>\frac{\alpha_{1}-\bar{\alpha}_{u}}{\alpha_{1}}$. We show later that this condition is satisfied for $\delta \geq \delta_{1}$.

3. Show that for each $s=1, \ldots, k-1$, constraint $s$ is either binding or $p_{s}=1$. Consider constraint $s$ and suppose otherwise that the constraint is not binding and that $p_{s}<1$. By increasing $p_{s}$ until either $p_{s}=1$ or constraint $s$ is binding, the objective function $v$ is increased and all the constraints in (14) are satisfied, leading to a contradiction.

4. Next, we show that for each $s=1, \ldots, k-1$, if $p_{s}=1$ then $p_{s-1}=1$. If $p_{s}=1$ then constraint $s$ becomes $v_{s} \geq \alpha_{1}$. Constraint $s-1$ stipulates $v_{s-1} \geq \alpha_{1} p_{s-1}$. From (10), $v_{s-1}=$ $\delta v_{s}+\pi_{s-1}$. Because fringe firms undercut, $\pi_{s-1}=\bar{\alpha}_{u} p_{s-1}$. Combining this information into constraint $s-1$ gives $v_{s} \geq \frac{\alpha_{1}-\bar{\alpha}_{u}}{\delta} p_{s-1}$. With $\delta>\frac{\alpha_{1}-\bar{\alpha}_{u}}{\alpha_{1}}$, this implies that $p_{s-1}=1$ satisfies constraint $s-1$.

5. We next show that $p_{s}=\min \left\{1, \frac{\delta \alpha_{1}}{\alpha_{1}-\bar{\alpha}_{u}} p_{s+1}\right\}, s=1, \ldots, k-2$. First, note that if constraint $s+1$ is not binding then $p_{s}=1$. Alternatively, suppose constraint $s+1$ is binding. We can use (10) to transform constraint $s$ to obtain $\delta v_{s+1}+\bar{\alpha}_{u} p_{s} \geq \alpha_{1} p_{s}$. Using the fact that constraint $s+1$ is 
binding, we obtain $\delta \alpha_{1} p_{s+1}+\bar{\alpha}_{u} p_{s} \geq \alpha_{1} p_{s}$ or $p_{s} \leq \frac{\delta \alpha_{1}}{\alpha_{1}-\bar{\alpha}_{u}} p_{s+1}$. Applying point 4 . above yields our desired result.

6. Let us prove that $p_{k-1}=\min \left\{1, \frac{\delta^{2} v_{1}}{\alpha_{1}-\bar{\alpha}_{u}}\right\}$. From (10), $v_{k-1}=\delta v_{k}+\pi_{k-1}$. Because the fringe undercuts, $\pi_{k-1}=\bar{\alpha}_{u} p_{k-1}$. Integrating the above into constraint $k-1$, we obtain $\delta v_{k}+\bar{\alpha}_{u} p_{k-1} \geq \alpha_{1} p_{k-1}$. Using the fact that $p_{k}=0$, we obtain $v_{k}=\delta v_{1}$. Combining these relationships gives $p_{k-1} \leq \frac{\delta^{2} \nu_{1}}{\alpha_{1}-\bar{\alpha}_{u}}$. Applying point 4 . above yields our desired result.

7. Let us prove that $v=v_{1}$. Note that point 5. and the fact that $\delta>\frac{\alpha_{1}-\bar{\alpha}_{u}}{\alpha_{1}}$ imply $p_{1} \geq p_{2} \geq \cdots \geq$ $p_{k-1}$. In addition, $p_{k}=0$ implies that $p_{k-1}>p_{k}$. The result follows immediately.

8. We now show that $p_{1}=1$. Notice that all constraints are homogeneous of degree one with respect to prices. We first prove by contradiction that $\max _{i} p_{i}=1$. With a choke price of $1, p_{i} \leq 1 \forall i$. Suppose that $\max _{i} p_{i}<1$. Introduce the variables $p_{s}^{\prime}=p_{s} / \max _{i} p_{i} \forall s \leq k$. Because of first degree homogeneity, our transformed variables must satisfy the constraints. Given that $p_{s}^{\prime}>p_{s} \forall i$, this means that $v^{\prime}>v$. Consequently, there is a contradiction and $\max _{i} p_{i}=1$. Monotonicity of $p_{s}$ in $s$ then ensures that $p_{1}=1$.

9. Next, we show that $\forall \delta$, the optimal sequence $\left\{p_{i}\right\}_{i=1}^{k}$, if it exists, must be unique. Suppose instead that there are two sequences. $v_{1}$ must be the same for both sequences, otherwise the one with the higher $v_{1}$ is chosen. This will uniquely determine the value of $p_{k-1}$ and then, recursively, $p_{k-2}, \ldots, p_{1}$. The optimal sequence is therefore unique.

10. Next, we derive $\delta_{1}$. Consider the situation when all constraints are binding. From constraint $k-1$ it follows that $v_{k-1}=\alpha_{1} p_{k-1}$. Using (10) and $\pi_{k-1}=\bar{\alpha}_{u} p_{k-1}$, it follows that $v_{k}=\frac{\alpha_{1}-\bar{\alpha}_{u}}{\delta \alpha_{1}} v_{k-1}$. Continuing this process results in

$$
v_{k}=\left(\frac{\alpha_{1}-\bar{\alpha}_{u}}{\delta \alpha_{1}}\right)^{k-i} v_{i}, \quad i=1, \ldots, k-1
$$

In particular, $v_{k}=\left(\frac{\alpha_{1}-\bar{\alpha}_{u}}{\delta \alpha_{1}}\right)^{k-1} v_{1}$. Then using $v_{k}=\delta v_{1}$, results in equation (17).

11. Let us prove that $v_{1}>v_{2}>\cdots>v_{k}$. Without loss of generality, suppose that $p_{s-1}=1$ and $p_{s}<1$. From equation (37) it immediately follows that $v_{s}>v_{s+1}>\cdots>v_{k}$. Next, note that for $i<s, \pi_{i}=\bar{\alpha}_{u}$ and for $i \geq s, \pi_{i}<\bar{\alpha}_{u}$. Therefore, $(1-\delta) \nu_{i}<\bar{\alpha}_{u}$ for $i<s$. From equation (10), $v_{i}=\delta v_{i+1}+\bar{\alpha}_{u}$. Combining these two expressions gives $v_{i}-\delta v_{i+1}>(1-\delta) v_{i}$ or $v_{i}>v_{i+1}$ for $i<s$.

12. Next, note that $v_{1}(\delta)$ is strictly increasing in $\delta$, where $v_{1}(\delta)$ is the value of $v_{1}$ associated with the optimal price sequence for discount factor $\delta$. Consider any two discount factors $\delta$ and $\delta^{\prime}$ with $\delta^{\prime}>\delta$. Let $\sigma^{(k)}(\delta)$ be the optimal price path associated with $\delta$. Then, abusing notation slightly, $\nu_{1}\left(\delta^{\prime}, \sigma^{(k)}\left(\delta^{\prime}\right)\right)>v^{1}\left(\delta^{\prime}, \sigma^{(k)}(\delta)\right)>v^{1}\left(\delta, \sigma^{(k)}(\delta)\right)$, as required.

13. By 5,6 , and 12 , all prices are increasing in $\delta$. 
14. We now show that this type of multi-price equilibrium exists if and only if $\delta_{1} \leq \delta \leq 1$. Recall that when $\delta=\delta_{1}$, constraint 1 in (14) is binding and $v_{1}=\alpha_{1}$. Because $v_{1}$ is strictly increasing in $\delta$, if $\delta<\delta_{1}$ then $v_{1}<\alpha_{1}$, leading to violation of constraint 1. Similarly, if $\delta>\delta_{1}$ then $v_{1}>\alpha_{1}$ and constraint 1 is satisfied.

15. From (17) it follows $\delta>\frac{\alpha_{1}-\bar{\alpha}_{u}}{\alpha_{1}}$, as required in step 2 .

16. Finally, we characterise the optimal path in terms of values rather than prices. Using the fact that $p_{k}=0$, we obtain $v_{k}=\delta v_{1}$. Next, consider the constraints for each period $s$ for $s<k$. Noting that $p_{s} \leq 1$ and using (10) yields $v_{s} \leq \bar{\alpha}_{u}+\delta v_{s+1}$. Using constraint $s$ and (10) leads to $v_{s} \leq \frac{\delta \alpha_{1}}{\alpha_{1}-\bar{\alpha}_{u}} v_{s+1}$. Employing the complementary slackness conditions of 3 ) then yields $v_{s}=\min \left\{\bar{\alpha}_{u}+\delta v_{s+1}, \frac{\delta \alpha_{1}}{\alpha_{1}-\bar{\alpha}_{u}} v_{s+1}\right\}$.

\section{Lemma 4}

The proof of part 1) is based on three observations. First, at the knot discount factor $\delta_{s}$, $p_{s}=1$, and constraint $s$ is binding so that $v_{s}=\alpha_{1}$. Second, all constraints $i \geq s$ are binding, so equation (37) applies. Third, for $i \leq s, p_{i}=1$. Therefore, each cartel member earns profits $\pi_{i}=\bar{\alpha}_{u}$ for $i \leq s$. Recursively applying (10), we have

$$
v_{1}=\bar{\alpha}_{u}\left(1+\delta+\cdots+\delta^{s-2}\right)+\delta^{s-1} \alpha_{1} .
$$

In period $k, \pi_{k}=0$. Applying (10) one more time gives

$$
v_{k}=\bar{\alpha}_{u} \sum_{i=1}^{s-1} \delta^{i}+\delta^{s} \alpha_{1}
$$

Combining equations (37) and (38), leads to (18).

To show part 2), we first let $s=k-1$. That is, consider the range $\delta \in\left[\delta_{k-1}, 1\right)$ and recall that there is a sales path in this range. Profits in each period $q<k$ are therefore $\pi_{q}=\bar{\alpha}_{u}$, and profits in period $k$ are $\pi^{k}=0$. Using (10), note that $v_{1}=\frac{\left(1+\delta+\cdots+\delta^{k-2}\right) \bar{\alpha}_{u}}{1-\delta^{k}}$, which results in $v_{1}=\frac{\left(1-\delta^{k-1}\right) \bar{\alpha}_{u}}{\left(1-\delta^{k}\right)(1-\delta)}$.

Now using a similar approach let us prove the statement for any $s=1, \ldots, k-2$. That is, consider the range $\delta \in\left[\delta_{s}, \delta_{s+1}\right)$. Profits are given by $\pi_{q}=\bar{\alpha}_{u}$ for $q \leq s, \pi_{q}=\bar{\alpha}_{u} p_{q}$ for $s<q<k$, and $\pi_{k}=0$. Hence,

$$
v_{1}=\frac{\left(1+\delta+\cdots+\delta^{s-1}+\delta^{s} p_{s+1}+\cdots+\delta^{k-2} p_{k-1}\right) \bar{\alpha}_{u}}{\left(1-\delta^{k}\right)} .
$$

Note that for $\delta \in\left[\delta_{s}, \delta_{s+1}\right)$, the following condition holds: $0=p_{k}<p_{k-1}<\cdots<p_{s+1}<1$. From Lemma 3, it then follows that $p_{k-1}=\frac{\delta^{2} v_{1}}{\alpha_{1}-\bar{\alpha}_{u}}, p_{k-2}=\left(\frac{\delta \alpha_{1}}{\alpha_{1}-\bar{\alpha}_{u}}\right) \frac{\delta^{2} v_{1}}{\alpha_{1}-\bar{\alpha}_{u}}, \ldots, p_{s+1}=\left(\frac{\delta \alpha_{1}}{\alpha_{1}-\bar{\alpha}_{u}}\right)^{k-s-2} \frac{\delta^{2} v_{1}}{\alpha_{1}-\bar{\alpha}_{u}}$. Combining these conditions with (39) results in (19), as required. 


\section{Lemma 5}

If $\chi \geq \alpha_{n} / \alpha_{1}$, then $p_{k-1}\left(\delta_{1}\right) \geq p_{k-1}(\hat{\delta})$. By Lemma 3, $p_{k-1}$ is increasing in $\delta$. Therefore, the critical discount factor is $\delta_{1}$. By the same argument, it follows that if $\chi<\alpha_{n} / \alpha_{1}$, then $\hat{\delta}$ is the critical discount factor.

\section{Lemma 6}

Let $\left\{p_{s}\right\}_{s=1}^{k}$ solve the program (12) - (14). First, we consider the incentive for the cartel to induce the fringe to relent. In period $s$, if the fringe firms undercut the cartel price, cartel members receive profits $\pi_{s}=\bar{\alpha}_{u} p_{s}$. To induce the fringe to relent, the cartel must set a price no higher than $\alpha_{n} / \alpha_{1}$, yielding profits of $\bar{\alpha}_{r} \alpha_{n} / \alpha_{1}$. Therefore, for $p_{s} \geq a$, the cartel prefers the fringe firms to undercut in period $s$. By Lemma 3, $p_{s}(\delta)$ is increasing in $\delta$ and decreasing in $s$. Therefore, $\chi \equiv p_{k-1}\left(\delta_{1}\right) \geq a$ is a sufficient condition.

Next, consider the feasibility of an equilibrium in which the fringe relents. Because $p_{s}(\delta)$ is decreasing in $s$, it is sufficient for us to consider period $k-1$. There is never an incentive for the fringe to relent if $p_{k-1}=1$. If $p_{k-1}<1$, then the cartel's undercutting constraint in period $k-1$ must bind and $v_{k-1}=\alpha_{1} p_{k-1}$. If the fringe relents in period $k-1$, then the cartel's relenting constraint becomes $v_{k-1} \geq \alpha_{n-1}$ or $p_{k-1} \geq \eta$. Thus, if $\chi<\eta$, the cartel is not sustainable if the fringe relents. Finally, note that it is only when the cartel prefers the fringe to relent (i.e. when $\chi<a$ ), that we need to satisfy this additional condition $\chi<\eta$. Combining these conditions, the relationship $\max \{\eta, \chi\} \geq a$ is sufficient to ensure an optimal market equilibrium contains an undercutting fringe.

\section{Proposition 1}

We first introduce the following intermediate result. Lemma 10 describes the nature of the optimal price path in the general case in which fringe manipulation is possible. Recall that the decision to encourage fringe relenting depends on both its optimality and feasibility. In Lemma 10, we provide conditions on the value function that satisfy these two constraints. In each period $s$ of the cycle, if $v_{s}$ is sufficiently low, then the cartel would like the fringe to relent, but if $v_{s}$ is sufficiently high, a relenting fringe is incompatible with the cartel's relenting incentive constraints. If these constraints overlap, this defines a range of values for $v_{s}$ over which the cartel sets a price of $\alpha_{n} / \alpha_{1}$ to manipulate the fringe into relenting.

Lemma 10. The $k$-period cycle $\sigma^{(k)}$ that solves the program (12) - (15) is unique and has the following properties: 
(i) values decline monotonically over the cycle: $v_{1} \geq v_{2} \geq \cdots \geq v_{k} . v=v_{1}$ is an increasing function of $\delta$ and

$$
\begin{gathered}
v_{s}= \begin{cases}\frac{\alpha_{n} \bar{\alpha}_{r}}{\alpha_{1}}+\delta v_{s+1} & \text { if } v_{s+1} \in\left[\frac{\alpha_{n-1}-\alpha_{n} \bar{\alpha}_{r} / \alpha_{1}}{\delta}, \frac{\alpha_{1}-\bar{\alpha}_{u}}{\delta} a\right) ; \\
\min \left\{\bar{\alpha}_{u}+\delta v_{s+1}, \frac{\delta \alpha_{1}}{\alpha_{1}-\bar{\alpha}_{u}} v_{s+1}\right\} & \text { otherwise. }\end{cases} \\
s=1, \ldots, k-1, \text { and } v_{k}=\delta v_{1} .
\end{gathered}
$$

(ii) prices are increasing in $\delta$ and decline monotonically over the cycle: $p_{1} \geq p_{2} \geq \cdots>p_{k}$, with $p_{1}=1, p_{k}=0$,

$$
p_{s}= \begin{cases}\frac{\alpha_{n}}{\alpha_{1}} & \text { if } v_{s+1} \in\left[\frac{\alpha_{n-1}-\alpha_{n} \bar{\alpha}_{r} / \alpha_{1}}{\delta}, \frac{\alpha_{1}-\bar{\alpha}_{u}}{\delta} a\right) \\ \min \left\{1, \frac{\delta \alpha_{1}}{\alpha_{1}-\bar{\alpha}_{u}} p_{s+1}\right\} & \text { otherwise }\end{cases}
$$

$s=1, \ldots, k-2$, and

$$
p_{k-1}= \begin{cases}\frac{\alpha_{n}}{\alpha_{1}} & \text { if } v_{1} \in\left[\frac{\alpha_{n-1}-\alpha_{n} \bar{\alpha}_{r} / \alpha_{1}}{\delta^{2}}, \frac{\alpha_{1}-\bar{\alpha}_{u}}{\delta^{2}} a\right) \\ \min \left\{1, \frac{\delta^{2} v_{1}}{\alpha_{1}-\bar{\alpha}_{u}}\right\} & \text { otherwise. }\end{cases}
$$

Proof. 1) We follow the proof of Lemma 3 and make adjustments when necessary. In Lemma 3 we characterised the optimal path in terms of prices and values when the fringe undercuts in every period:

$$
p_{1}=1, p_{s}=\min \left\{1, \frac{\delta \alpha_{1}}{\alpha_{1}-\bar{\alpha}_{u}} p_{s+1}\right\}, s=1, \ldots, k-2, p_{k-1}=\min \left\{1, \frac{\delta^{2} v_{1}}{\alpha_{1}-\bar{\alpha}_{u}}\right\} \text { and } p_{k}=0
$$

and

$$
v_{s}=\min \left\{\bar{\alpha}_{u}+\delta v_{s+1}, \frac{\delta \alpha_{1}}{\alpha_{1}-\bar{\alpha}_{u}} v_{s+1}\right\}, s=1, \ldots, k-1, \text { and } v_{k}=\delta v_{1} .
$$

2) In Lemma 6 we showed that for $p_{s} \geq a$ the cartel prefers the fringe firm to undercut in period $s$. If the fringe is induced to relent, the cartel must set a price no higher than $\alpha_{n} / \alpha_{1}$, yielding profits of $\bar{\alpha}_{r} \alpha_{n} / \alpha_{1}$. Therefore from equation (10), if the fringe is induced to relent,

$$
p_{s}=\alpha_{n} / \alpha_{1} \text { and } v_{s}=\bar{\alpha}_{r} \alpha_{n} / \alpha_{1}+\delta v_{s+1}
$$

Observe that in (44) $v_{s}=\bar{\alpha}_{u}+\delta v_{s+1}$ corresponds to the case $p_{s}=1$. Comparing to (45), in this case, the cartel prefers the fringe to relent if and only if $a>1$, a contradiction. Alternatively, if $v_{s}=\frac{\delta \alpha_{1}}{\alpha_{1}-\bar{\alpha}_{u}} v_{s+1}$ in (44), comparing with (45) gives the following condition for when it is profitable to induce the fringe to relent:

$$
v_{s+1}<\frac{\alpha_{1}-\bar{\alpha}_{u}}{\delta} a
$$


Note also that the value given by (45) has to be higher than $\alpha_{n-1}$, otherwise the cartel is not sustainable. This results in the following condition:

$$
v_{s+1}>\frac{\alpha_{n-1}-\alpha_{n} \bar{\alpha}_{r} / \alpha_{1}}{\delta}
$$

Consequently, from (46) and (47), inducing the fringe to relent given by equation (45) is both optimal and feasible when

$$
v_{s+1} \in\left[\frac{\alpha_{n-1}-\alpha_{n} \bar{\alpha}_{r} / \alpha_{1}}{\delta}, \frac{\alpha_{1}-\bar{\alpha}_{u}}{\delta} a\right)
$$

3) Next, follow all steps from point 7 in Lemma 3. Note that monotonicity holds in the general case because (45), when applied instead of (44), increases both $p_{s}$ and $v_{s}$ monotonically.

With Lemma 10 established, we return to the proof of Proposition 1. Consider the candidate solution $\left\{p_{s}, b_{s}, v_{s}\right\}_{s=1}^{k}$.

1. If the fringe relents, the cartel obtains a market share of $\bar{\alpha}_{r}$. If the fringe undercuts, the cartel receives $\bar{\alpha}_{u}$. To induce the fringe to relent in period $s$, the cartel must set a revenue of $\alpha_{n} / \alpha_{1}$. The cartel therefore prefers the fringe to undercut if $\frac{\bar{\alpha}_{r} \alpha_{n}}{\alpha_{1}}<\bar{\alpha}_{u} p_{s}$ or

$$
p_{s}>\frac{\alpha_{n} \bar{\alpha}_{r}}{\alpha_{1} \bar{\alpha}_{u}}=a
$$

2. In Lemma 3, we established the monotonicity of $p_{s}$ in $s$ in the case where the fringe undercuts in all periods. By monotonicity, if (49) holds for $s=k-1$ then it must hold for $s<k-1$. This establishes the first condition required for optimality of $\left\{p_{s}^{(0)}, b_{s}^{(0)}, v_{s}^{(0)}\right\}_{s=1}^{k}$. The second condition describes when the relenting is not feasible. Again by monotonicity of value functions, $v_{k} \leq v_{k-1} \leq \cdots \leq v_{2}<\frac{\alpha_{n-1}-\alpha_{n} \bar{\alpha}_{r} / \alpha_{1}}{\delta}$.

3. Next, we describe the construction of $p_{s}^{(q, r)}$ in (25). Consider $r=k-1$. The cartel induces the fringe to undercut for $s<q$ and $s=k$ and induces relenting for $s \in[q, k-1]$. Therefore $p_{k}^{(q, k-1)}=0$ and $p_{s}^{(q, k-1)}=\alpha_{n} / \alpha_{1}$ for $s \in[q, k-1]$. Using (10), $v_{k}^{(q, k-1)}=\delta v_{1}^{(q, k-1)}, v_{k-1}^{(q, k-1)}=$ $\delta^{2} v_{1}^{(q, k-1)}+\frac{\alpha_{n} \bar{\alpha}_{r}}{\alpha_{1}}$ and interactively $v_{s}^{(q, k-1)}=\delta^{k-s+1} v_{1}^{(q, k-1)}+\frac{\alpha_{n} \bar{\alpha}_{r}}{\alpha_{1}} \sum_{0}^{k-s-1} \delta^{m}$ for any $s \in[q, k-$ $1]$.

Next consider period $q-1$. Using (40), $v_{q-1}^{(q, k-1)}=\left(\frac{\alpha_{1}-\bar{\alpha}_{u}}{\delta \alpha_{1}}\right)^{q-2} v_{1}^{(q, k-1)}$. The cartel undercutting constraint in period $q-1$ is $v_{q-1}^{(q, k-1)} \geq \alpha_{1} p_{q-1}^{(q, k-1)}$. Combining these conditions and rearranging, we have

$$
p_{q-1}^{(q, k-1)} \leq \frac{1}{\alpha_{1}}\left(\frac{\alpha_{1}-\bar{\alpha}_{u}}{\delta \alpha_{1}}\right)^{q-2} v_{1}^{(q, k-1)}
$$


Optimality of the revenue path requires $p_{q-1}^{(q, k-1)}$ to be as high as possible without exceeding the monopoly revenue of 1 . Therefore,

$$
p_{q-1}^{(q, k-1)}=\min \left\{1, \frac{1}{\alpha_{1}}\left(\frac{\alpha_{1}-\bar{\alpha}_{u}}{\delta \alpha_{1}}\right)^{q-2} v_{1}^{(q, k-1)}\right\} .
$$

For periods $s=2, \ldots, q-2$, apply the same steps as point 5 . in Lemma 3. This yields

$$
p_{s}^{(q, k-1)}=\min \left\{1, \frac{\delta \alpha_{1}}{\alpha_{1}-\bar{\alpha}_{u}} p_{s+1}^{(q, k-1)}\right\}, s=2, \ldots, q-2 .
$$

4. Next, we describe the construction of $p_{s}^{(q, r)}$ in (26). Consider $r<k-1$. The cartel induces the fringe to undercut for $s<q$ and $s>r$ and induces relenting for $s \in[q, r]$. Therefore $p_{k}^{(q, r)}=0$ and $p_{s}^{(q, r)}=\alpha_{n} / \alpha_{1}$ for $s \in[q, r]$. Using (10) and (40), $v_{k}^{(q, r)}=\delta v_{1}^{(q, r)}, v_{k-1}^{(q, r)}=$ $\frac{\delta^{2} \alpha_{1}}{\alpha_{1}-\bar{\alpha}_{u}} v_{1}^{(q, r)}$ and interactively $v_{s}^{(q, r)}=\delta\left(\frac{\delta \alpha_{1}}{\alpha_{1}-\bar{\alpha}_{u}}\right)^{k-s} v_{1}^{(q, r)}$ for any $s \in[r+1, k-2]$. Similarly, $v_{2}^{(q, r)}=\frac{\alpha_{1}-\bar{\alpha}_{u}}{\delta \alpha_{1}} v_{1}^{(q, r)}$ and interactively $v_{s}^{(q, r)}=\left(\frac{\alpha_{1}-\bar{\alpha}_{u}}{\delta \alpha_{1}}\right)^{s-1} v_{1}^{(q, r)}$ for any $s \in[2, q-1]$. This means $p_{k-1}^{(q, r)}=\min \left\{1, \frac{\delta^{2} v_{1}^{(q, r)}}{\alpha_{1}-\bar{\alpha}_{u}}\right\}$ and $p_{s+1}^{(q, r)}=\min \left\{1, \frac{\delta \alpha_{1}}{\alpha_{1}-\bar{\alpha}_{u}} p_{s+1}^{(q, r)}\right\}$ for any $s \in[2, q-2] \cup[r+1, k-2]$.

Next consider period $q-1$. As we showed earlier $v_{q-1}^{(q, r)}=\left(\frac{\alpha_{1}-\bar{\alpha}_{u}}{\delta \alpha_{1}}\right)^{q-2} v_{1}^{(q, r)}$. The cartel undercutting constraint in period $q-1$ is $v_{q-1}^{(q, r)} \geq \alpha_{1} p_{q-1}^{(q, r)}$. Combining these conditions and rearranging, we have

$$
p_{q-1}^{(q, r)} \leq \frac{1}{\alpha_{1}}\left(\frac{\alpha_{1}-\bar{\alpha}_{u}}{\delta \alpha_{1}}\right)^{q-2} v_{1}^{(q, r)}
$$

Optimality of the revenue path requires $p_{q-1}^{(q, r)}$ to be as high as possible without exceeding the monopoly revenue of 1 . Therefore,

$$
p_{q-1}^{(q, r)}=\min \left\{1, \frac{1}{\alpha_{1}}\left(\frac{\alpha_{1}-\bar{\alpha}_{u}}{\delta \alpha_{1}}\right)^{q-2} v_{1}^{(q, r)}\right\} .
$$

5. Next, from Lemma 10 it follows that $p_{1}^{(q, r)}=1$.

6. Next, we derive $\delta_{1}$. Consider the situation when the fringe is relenting in periods $s \in[q, r]$, $r<k-1$ and all constraints are binding. Using (40), it follows that $v_{2}=\frac{\alpha_{1}-\bar{\alpha}_{u}}{\delta \alpha_{1}} v_{1}$. Continuing this process results in

$$
v_{s}=\left(\frac{\alpha_{1}-\bar{\alpha}_{u}}{\delta \alpha_{1}}\right)^{s-1} v_{1}, \quad s=2, \ldots, q
$$

In particular, $v_{q}=\left(\frac{\alpha_{1}-\bar{\alpha}_{u}}{\delta \alpha_{1}}\right)^{q-1} v_{1}$.

On the other hand, $v_{k}=\delta v_{1}$. From (40) $v_{k-1}=\frac{\delta^{2} \alpha_{1}}{\alpha_{1}-\bar{\alpha}_{u}} v_{1}$ and recursively $v_{q+1}=\delta\left(\frac{\delta \alpha_{1}}{\alpha_{1}-\bar{\alpha}_{u}}\right)^{k-r-1} v_{1}$. 
In addition from (40), $v_{q}=\frac{\alpha_{n} \bar{\alpha}_{r}}{\alpha_{1}}+\delta v_{q+1}$ and recursively

$$
v_{q}=\frac{\alpha_{n} \bar{\alpha}_{r}}{\alpha_{1}} \sum_{u=0}^{r-q} \delta^{u}+\delta^{r-q+1} v_{r+1} .
$$

Using the first binding constraint $\nu_{1}=\alpha_{1}$, it follows that

$$
\delta_{1}^{k}\left(\frac{\alpha_{1}-\bar{\alpha}_{u}}{\alpha_{1}}\right)^{r-k}+\frac{\alpha_{n} \bar{\alpha}_{r}}{\alpha_{1}^{2}} \sum_{u=q-1}^{r-2} \delta_{1}^{u}=\left(\frac{\alpha_{1}-\bar{\alpha}_{u}}{\alpha_{1}}\right)^{q-1} .
$$

7. By the monotonicity of (40), there is a unique solution that satisfies for some $q$ and $r$ two conditions $p_{q}^{(q+1, r)}<a<p_{q-1}^{(q, r)}$ and $v_{r+1}^{(q, r+1)}<\frac{\alpha_{n-1}-\alpha_{n} \bar{\alpha}_{r} / \alpha_{1}}{\delta}<v_{r}^{(q, r)}$. This concludes the proof.

\section{Corollary 1}

1. First, note that $v_{s}$ is monotonically declining in $s$. Therefore, the relenting constraints in (15) are satisfied if and only if $v_{k-1} \geq \alpha_{n-1}$. Using (10), we have $v_{k-1}=\frac{\alpha_{n} \bar{\alpha}_{r}}{\alpha_{1}}+\delta^{2} v_{1}$. Combining yields

$$
v_{1} \geq \frac{\alpha_{n-1}-\alpha_{n} \bar{\alpha}_{r} / \alpha_{1}}{\delta^{2}}
$$

2. If $\delta=\delta_{1}$, all the undercutting constraints in (14) are binding and $v_{1}=\alpha_{1}$. Satisfying the undercutting constraints therefore requires $v_{1} \geq \alpha_{1}$.

3. Undercutting and relenting temptations are equated when

$$
\alpha_{1}=\frac{\alpha_{n-1}-\alpha_{n} \bar{\alpha}_{r} / \alpha_{1}}{\delta^{2}}
$$

This occurs at the discount factor

$$
\delta^{\prime}=\left(\frac{\alpha_{n-1}}{\alpha_{1}}-\frac{\alpha_{n} \bar{\alpha}_{r}}{\alpha_{1}^{2}}\right)^{1 / 2} .
$$

4. Now we derive $\delta_{1}$. Consider the situation when the fringe is relenting in periods $s \in$ $[q, k-1]$ and all constraints are binding. Using (40), it follows that $v_{2}=\frac{\alpha_{1}-\bar{\alpha}_{u}}{\delta \alpha_{1}} v_{1}$. Continuing this process results in

$$
v_{s}=\left(\frac{\alpha_{1}-\bar{\alpha}_{u}}{\delta \alpha_{1}}\right)^{s-1} v_{1}, \quad s=2, \ldots, q .
$$

In particular, $v_{q}=\left(\frac{\alpha_{1}-\bar{\alpha}_{u}}{\delta \alpha_{1}}\right)^{q-1} v_{1}$. Next from (40), $v_{q}=\frac{\alpha_{n} \bar{\alpha}_{r}}{\alpha_{1}}+\delta v_{q+1}$ and recursively

$$
v_{q}=\frac{\alpha_{n} \bar{\alpha}_{r}}{\alpha_{1}} \sum_{u=0}^{k-q-1} \delta^{u}+\delta^{k-q} v_{k}
$$


Using $v_{k}=\delta v_{1}$ and the first binding constraint $v_{1}=\alpha_{1}$, it follows that

$$
\delta_{1}^{k}+\frac{\alpha_{n} \bar{\alpha}_{r}}{\alpha_{1}^{2}} \sum_{u=q-1}^{k-2} \delta_{1}^{u}=\left(\frac{\alpha_{1}-\bar{\alpha}_{u}}{\alpha_{1}}\right)^{q-1}
$$

5. Both undercutting and relenting constraints are binding at the same discount factor when $\delta_{1}=\delta^{\prime}$. Consequently, $\delta^{\prime} \leq \delta_{1}$.

\section{Lemma 7}

First, if $\chi \geq \alpha_{n} / \alpha_{1}$, then $p_{k-1}\left(\delta_{1}\right) \geq p_{k-1}(\hat{\delta})$. By Lemma 10, $p_{k-1}$ is increasing in $\delta$. Second, if $r=k-1$, then $v_{k-1} \geq \alpha_{n-1}$. By Lemma 10, all values decline monotonically over the cycle, and therefore $v_{1} \geq \cdots \geq v_{k-1} \geq \alpha_{n-1}$. In both cases, the critical discount factor is $\delta_{1}$. If neither of the above conditions are satisfied, by the same argument, it follows that $\hat{\delta}$ is the critical discount factor.

\section{Corollary 2}

Lemma 1 implies that in the optimal fixed price path, $p=\alpha_{n}$, and the path is sustainable iff $\delta \geq \delta_{0}$. The optimal fringe response is to marginally undercut the cartel price in period 1 of the cycle by setting a price of $\hat{\alpha}_{n}$, and relent by setting a price of 1 in all other periods. Cartel members receive profits of 0 in period 1 , and $\alpha_{n} \bar{\alpha}_{r}$ in all other periods. This implies that, after period 1 , values decline monotonically over the cycle, $v_{2}>v_{3}>\cdots>v_{k}$. By Lemma 2, the cartel faces internal incentive constraints of $v_{1} \geq \alpha_{n-1}$ in period 1 , and $v_{s} \geq \alpha_{1} p$ in periods $2, \ldots, k$. By the monotonicity of values, it follows that the constraints $v_{s} \geq \alpha_{1} p$ must be slack for $s \in\{2, \ldots, k-1\}$. Because all values are continuous functions of $\delta$, there exists an alternative higher-value path $\left\{\tilde{p}_{s}\right\}_{s=1}^{k}$ with $\tilde{p}_{1}=\tilde{p}_{k}=p$ and $\tilde{p}_{s} \in\left(p, p / \alpha_{1}\right]$ for $s \in\{2, \ldots, k-1\}$ with critical discount value below $\delta_{0}$. By construction, fringe behaviour is unchanged in the new path. Finally, by Proposition 1, there exists an optimal path with higher value and lower critical discount factor than the constructed path.

\section{Proposition 2}

Let us show that the optimal $k$ period path dominates all shorter paths. Suppose instead that the path $\left\{\tilde{p}_{s}\right\}_{s=1}^{l}$ is optimal, with $l<k$. Prepend $p_{0}^{\prime}=1$ to form the path $\left\{p_{s}^{\prime}\right\}_{s=0}^{l}$, where $p_{s}^{\prime}=\tilde{p}_{s}$ for $s=1, \ldots, l$. Because $\tilde{p}_{s} \leq 1$ for $s=1, \ldots, l-1$, and $\tilde{p}_{l}=0$, the value of the new path is greater. 
Next, notice that $v_{s}^{\prime}>\tilde{v}_{s}$ for $s=1, \ldots, l$. Hence, if the incentive constraints were satisfied for the original path, then they must also be satisfied in periods $s=1, \ldots, l$ for the new path. Also observe that $p_{0}^{\prime}=p_{1}^{\prime}=1$ and $v_{0}^{\prime}>v_{1}^{\prime}$. Therefore, if the constraints in period 1 are satisfied, then the constraints in period 0 must also be satisfied. Thus, the $k$ period path is sustainable and of higher value than the $l$ period path, leading to a contradiction. Therefore, the optimal path is of length $k$ periods.

\section{Lemma 8}

Let $f>1$. Suppose initially that fringe firms adopt symmetric pure strategies. Then, because $\alpha_{r}>\alpha_{r+1}$ for $r=1, \ldots, n-1$, each fringe firm has a profitable deviation in which she marginally undercuts the price of her fringe rivals, leading to a contradiction.

Next, we seek a market equilibirum in which fringe firms adopt symmetric mixed strategies. Let $G_{t}(p)$ describe the cdf of $p$. For convenience, we drop the time subscript. We introduce the shorthand notation $\mathbb{E}_{-j}\left(s^{j} \mid p_{t}, G(p)\right)$ for the expected market share of fringe firm $j$ when cartel members set price $p_{t}$ and the other $f-1$ fringe firms adopt the distribution $G$. The expected profit of a fringe firm is $p \mathbb{E}_{-j}\left(s^{j} \mid p_{t}, G\right)$. Observe that $G$ does not have any mass points and $p_{t}$ is not in the support of $G$. Otherwise, it would be profitable to deviate by marginally undercutting $p_{t}$ or any mass point. This implies that $G$ must be continuous.

Suppose initially that fringe firms always undercut the cartel price in period $t$. Every price in the support of $G$ must be equally profitable, and hence $G$ has support $\left[\alpha_{f} p_{t} / \alpha_{1}, p_{t}\right)$. G(p) is defined implicitly by (32).

To show that $G(p)$ can be a cdf, let us prove that $G(p)$ is a unique and monotonically increasing function. Monotonicity follows from the following argument. The right-hand side of (32) does not depend on $p$, which implies that $p \frac{\partial \mathbb{E}_{-j}\left(s^{j} \mid p_{t}, G\right)}{\partial p}+\mathbb{E}_{-j}\left(s^{j} \mid p_{t}, G\right)=0$, and therefore that $\frac{\partial \mathbb{E}_{-j}\left(s^{j} \mid p_{t}, G\right)}{\partial p} \neq 0$. With $\frac{\partial \mathbb{E}_{-j}\left(s^{j} \mid p_{t}, G\right)}{\partial p}=\frac{\partial \mathbb{E}_{-j}\left(s^{j} \mid p_{t}, G\right)}{\partial G} \frac{\partial G}{\partial p}$, this means $\frac{\partial G(p)}{\partial p} \neq 0 . G\left(\alpha_{f} p_{t} / \alpha_{1}\right)=$ 0 and $G\left(p_{t}\right)=1$, and the derivative of $G(p)$ is never zero. Hence, $G(p)$ must be monotonically increasing.

To prove uniqueness, note that by the same argument, $\mathbb{E}_{-j}\left(s^{j} \mid p_{t}, G\right)$ is a monotonically decreasing function in $G$. It decreases from $\alpha_{1}$ to $\alpha_{f}$ as $G$ changes from 0 to 1 and its derivative is never zero as $\frac{\partial \mathbb{E}_{-j}\left(s^{j} \mid p_{t}, G\right)}{\partial p}=\frac{\partial \mathbb{E}_{-j}\left(s^{j} \mid p_{t}, G\right)}{\partial G} \frac{\partial G}{\partial p}$. Now, suppose instead that $G(p)$ is not unique for a given $p$. As $\mathbb{E}_{-j}\left(s^{j} \mid p_{t}, G\right)$ is monotonically decreasing in $G$, there are at least two different values of $\mathbb{E}_{-j}\left(s^{j} \mid p_{t}, G\right)$ corresponding to two different solutions $G(p)$. But $\mathbb{E}_{-j}\left(s^{j} \mid p_{t}, G\right)=$ $\alpha_{f} p_{t} / p$, which implies that the value of $\mathbb{E}_{-j}\left(s^{j} \mid p_{t}, G\right)$ is unique for a given $p$, leading to a contradiction. Consequently, $G(p)$ has to be unique.

Let us identify the conditions required for an equilibrium in which fringe firms always 
undercut in period $t$. By construction, there is no incentive to deviate to another price below $p_{t}$. The optimal relenting deviation involves setting a price of 1 and obtaining profits $\alpha_{n}$. This deviation is not profitable if $\alpha_{n} \leq \alpha_{f} p_{t}$ or $p_{t} \geq \alpha_{n} / \alpha_{f}$.

Now, suppose instead that fringe firms always relent in period $t$. The cdf $G(p)$ is implicitly defined by (33) on the support $\left[\alpha_{n} / \alpha_{n-f+1}, 1\right]$. By the above arguments, $G(p)$ is unique and monotonically increasing. Let us identify the conditions required for equilibrium. By construction, there is no incentive to deviate to another price above $p_{t}$. The optimal undercutting deviation is to marginally undercut the cartel price of $p_{t}$ and obtain profits of $\alpha_{1} p_{t}$. This deviation is unprofitable if $\alpha_{1} p_{t} \leq \alpha_{n}$ or $p_{t} \leq \alpha_{n} / \alpha_{1}$.

Next, suppose that fringe firms relent and undercut with positive probability. Then, the cdf $G(p)$ is implicitly defined by (34) on the support $\left[\alpha_{n} / \alpha_{1}, p_{t}\right) \cup[\widetilde{p}, 1]$, where $\widetilde{p}$ solves $G^{u}\left(p_{t} \mid \alpha_{n} / \alpha_{f}\right)=G^{r}(\widetilde{p})$. According to (34), the expected profits of each fringe firm are $\alpha_{n}$ for all prices in the support of $G$, and $G$ is a cdf by construction. Now, we identify the conditions needed for equilibrium. First, observe that for undercutting to occur with positive probability, $p_{t}>\alpha_{n} / \alpha_{1}$. Next, we show that $p_{t}<\alpha_{n} / \alpha_{f}$. Suppose otherwise that $p_{t} \geq$ $\alpha_{n} / \alpha_{f}$. Firms relent with positive probability, which implies that $G\left(\dot{p}_{t}\right)<1$. By (34), $\alpha_{n}=$ $\tilde{p}_{t} \mathbb{E}_{-j}\left(s^{j} \mid p_{t}, G^{u}\left(\dot{p}_{t} \mid \alpha_{n} / \alpha_{f}\right)\right)>p_{t} \alpha_{f}$, leading to a contradiction. Therefore, we must have $p_{t} \in\left(\alpha_{n} / \alpha_{1}, \alpha_{n} / \alpha_{f}\right)$. Finally, there is no incentive to deviate either above or below the cartel price. 


\section{References}

Willard D. Arant. Competition of the few among the many. The Quarterly Journal of Economics, 70:327-345, 1956.

Hassan Benchekroun and Cees Withagen. On price taking behavior in a nonrenewable resource cartel-fringe game. Games and Economic Behavior, 76:355-374, 2012.

Hassan Benchekroun, Gerard van der Meijden, and Cees Withagen. An oligopoly-fringe nonrenewable resource game in the presence of a renewable substitute. Journal of Economic Dynamics \& Control, 105:1-20, 2019.

Iwan Bos and Joseph E. Harrington. Endogenous cartel formation with heterogeneous firms. RAND Journal of Economics, 41:92-117, 2010.

Claude D’Aspremont and Jean Jaskold Gabszewicz. Quasi-monopolies. Economica, 52:141$151,1985$.

Claude D’Aspremont, Alexis Jacquemin, Jean Jaskold Gabszewicz, and John A. Weymark. On the stability of collusive price leadership. The Canadian Journal of Economics, 16:17-25, 1983.

Nicolas de Roos. Collusion with a competitive fringe: An application to vitamin C. Working paper, 2001.

Nicolas de Roos. Collusion with limited product comparability. RAND Journal of Economics, 49:481-503, 2018.

Nicolas de Roos and Vladimir Smirnov. Collusion with intertemporal price dispersion. University of Sydney Working paper, 2019.

Nicolas de Roos and Vladimir Smirnov. Collusion with intertemporal price dispersion. RAND Journal of Economics, forthcoming.

M.-P. Donsimoni, N.S. Economides, and H.M. Polimarchakis. Stable cartels. International Economic Review, 27:317-327, 1986.

Drew Fudenberg and Jean Tirole. Game Theory. MIT Press, Cambridge, MA, 1991.

James M. Griffin. Previous cartel experience: Any lessons for OPEC? In Lawrence R. Klein and Jaime Marquez, editors, Economics in Theory and Practice: An Eclectic Approach. Dordrecht: Kluwer Academic Publishers, 1989. 
Joseph Harrington. How do cartels operate? Foundations and Trends in Microeconomics, 2: $1-105,2006$.

George A. Hay and Daniel Kelley. An empirical survey of price fixing conspiracies. Journal of Law and Economics, 17:13-38, 1974.

Paul Heidhues and Botond Kőszegi. Behavioral industrial organization. In Handbook of Behavioral Economics, volume 1, pages 517-612. North Holland, 2018.

Val Eugene Lambson. Some results on optimal penal codes in asymmetric bertrand supergames. Journal of Economic Theory, 62:444-468, 1994.

Jesse W. Markham. The nature and significance of price leadership. The American Economic Review, 41:891-905, 1951.

Stephen Martin. Fringe size and cartel stability. EUI Working Paper ECO No. 90/16, 1990.

Stephen W. Salant. Exhaustible resources and industrial structure: a Nash approach to the world oil market. Journal of Political Economy, 84:1079-1094, 1976.

Sherrill Shaffer. Stable cartels with a Cournot fringe. Southern Economic Journal, 61:744-754, 1995.

Ran Spiegler. Bounded Rationality and Industrial Organization. Oxford University Press, 2011. 